This item was submitted to Loughborough's Research Repository by the author.

Items in Figshare are protected by copyright, with all rights reserved, unless otherwise indicated.

\title{
Predicting the onset of end-gas autoignition with a quasi-dimensional spark ignition engine model
}

PLEASE CITE THE PUBLISHED VERSION

PUBLISHER

(c) Society of Automotive Engineers

VERSION

VoR (Version of Record)

LICENCE

CC BY-NC-ND 4.0

\section{REPOSITORY RECORD}

Jenkin, R.J., E.H. James, and W. Malalasekera. 2019. "Predicting the Onset of End-gas Autoignition with a Quasi-dimensional Spark Ignition Engine Model”. figshare. https://hdl.handle.net/2134/5713. 
This item was submitted to Loughborough's Institutional Repository (https://dspace.lboro.ac.uk/) by the author and is made available under the following Creative Commons Licence conditions.

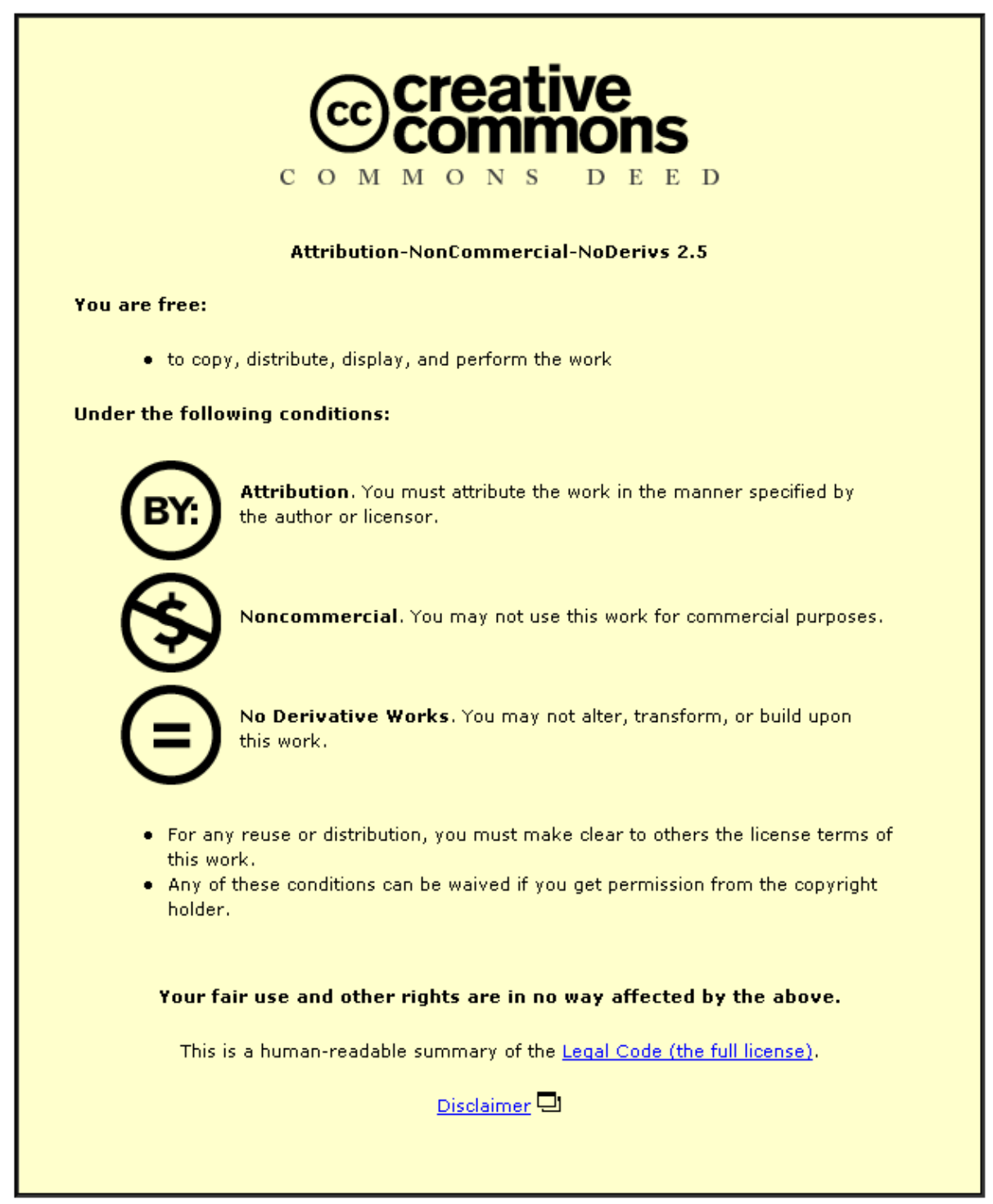

For the full text of this licence, please go to: http://creativecommons.org/licenses/by-nc-nd/2.5/ 


\section{Predicting the Onset of End-Gas Autoignition with a Quasi-Dimensional Spark Ignition Engine Model}

R. J. Jenkin, E. H. James, and W. Malalasekera Loughborough Univ.

Reprinted from: Diesel and SI Engine Modeling

(SP-1306) 


\title{
Predicting the Onset of End-Gas Autoignition with a Quasi-Dimensional Spark Ignition Engine Model
}

\author{
R. J. Jenkin, E. H. James, and W. Malalasekera \\ Loughborough Univ.
}

Copyright 1997 Society of Automotive Engineers, Inc.

\begin{abstract}
A predictive. quasi-dimensional simulation of combustion in a spark ignition engine has been coupled with a chemical kinetic model for the low temperature, pre-flame reactions of bydrocarbon fuel and air mixtures. The simulation is capable of predicting the onset of autoignition without prior knowledge of the cylinder pressure history. Near-wall temperature gradients were computed within the framework of the cngine cycle simulation by dividing the region into a number of thin mass slices which were assumed to remain adjacent to the combustion chamber surfaces in both the burned and unburned gas. The influence of the near-wall turbulence on the temperature field was accounted for by means of a boundary layer turbulence model developed by the authors. Fluid motion in the bulk gases has been considered by the inclusion of a turbulence model based on $k-s$, theory while the flame propagation rate was predicted using a fractal flame model. Validation of the engine-cycle simulation is afforded by comparison of predicted turbulence intensities. gas temperatures, gas-wall interface heat fluxes and pressure histories with appropriate measured values. All showed good agreement. The heat release from the preflame ractions was estimated using the reduced kinetic model and has been accounted for in the overall engine simulation energy balance. The chemical kinetic and engine cycle models were solved simultaneously enabling the simulation of the coupled effects of the heat release by the pre-flame reactions on the end-gas temperatures and the subsequent influence of these temperatures on the rates of reaction in the end-gas region as combustion proceeds. Validation of the model is afforded by comparison of cylinder pressure predictions with those measured in a knocking engine. After modifying the Arrhenius parameter for the chain branching reaction in the chemical kinetic model the knock onset time was accurately predicted. In this context, the model was then employed to demonstrate the influence of the flame propagation rate on the knock onset lime in a simulation of cyclically varying knock.
\end{abstract}

\section{INTRODUCTION}

Awareness of the finite limit to the oil reserves which provide a large proportion of our fuel for heating and motive purposes has led to continued investigation into ways of most economically utilising the resources available. Spark ignition internal combustion engines provide the power for the majority of passenger cars and small motorised utilities. The primary obstacle limiting significant improvement in the efficiency of such engines is the restriction imposed on the compression ratio by 'knock'. Engine 'knock' manifests itself as an audible sound resonating from the crank case. It is undesirable as it is a source of annoyance and in extreme cases can lead to permanent engine damage. Since lead additives in fuel have been eliminated or reduced in response to their detrimental environmental impact, much work has gone into increasing our understanding of the chemical and physical phenomena responsible for knock in order to enable the development of economic. higher octane fues without the use of tetramethyl-lead.

Affleck and Fish [1] simulated autoignition and rapid flame propagation in a rapid compression machinc and observed that as with knocking cycles in spark ignition engines, pressure diagrams from the autoignited cases cxhibited a sudden pressure rise after a 'cool down' phase. Due to the similarity between the characteristics of pressure diagrams measured during knocking engine operation and autoignition in rapid compression machines. they concluded that knock in engines was caused by the spontaneous autoignition of the end-gas. Cuttler and Girgis $|2|$ observed this to be the case also in a pancake shaped combustion chamber using high speed photography but hypothesised that results obtained in a 'compact' combustion chamber could be duc to rapid entrainment of the end-gas by extreme acceleration of the flame. As measurement techniques have become more sophisticated and an increasing amount of data is made available. a more detailed picture of the events leading up to engine knock has evolved. Stiebels et a/ $|3|$ captured flame images at the time of the rapid pressure rise associated with knock using very sensitive intensified CCD cameras. They were able to clearly identify the phenomenon of the apparent rapid flame propagation noted by Cutler and Girgis [2] as the misinterpretation of less informative Schlieren and natural light images. In actuality, the propagating flame was quickly merging with the autoigniting end-gas giving the impression of a rapidly accelerating flame. Griffiths and Nimmo $|4|$ concluded that the pressure oscillations associated with 
knock are driven by the extremely rapid rate of energy relcase in the end-gas due to combustion propagating from autoignition centres. Konig and Sheppard [5] noted similar phenomena when they simultancously recorded Schlieren images of the cylinder gas and the cylinder pressure. Their observations showed that knock was always preceded by autoignition but the occurrence of autoignition did not necessarily result in knock. In a companion paper, Konig et a) $|6|$ cxperimentally reproduced the three modes of autoignition identified by Zeldovich 17] and concluded that autoignition was most likely to be initiated at exothermic centres (ETCs) in the end-gas. Such conclusions were also reached by Griffills and Nimmo [4] and Steibels et al [3]. Konig et $a / \mathrm{s}|6|$ studies also indicated that the combustion initiated at such centres is most likely to proceed in deflagrative or developing detonation modes depending on the thermal state of the end-gas. Steibels et al [3] were able to cstimate the speed of the flames propagating from the ETCs and confirmed this. After some validation against observed pressures and flame images, Pan and Sheppard [8] used the LUMAD code (for the two-dimensional simulation of knock) $|6| .|8|$ to study the events leading up to knock and the modes of combustion after autoignition. Notably, they investigated the interaction of multiple ETCs in cases where the pressure rise due to flame propagation from one ETC modified the thermal state at other ETCs increasing the likelihood of the developing detonation mode of autoignition which Konig et al $|6|$ identified as the most destructive due to the large pressure oscillations induced by the supersonic gas velocitics.

Konig and Sheppard [5] also noted that the knock intensity correlated well with the time of knock onset. A further comparison of computed end gas temperatures at the time of knock onset correlated strongly with the measured knock intensity. Gabano et al 19$]$ observed considerable differences in the pressure development in a simulation of knock in a constant volume combustion bomb when different initial gas tomperatures were used. They concluded that this was predominantly duc to the influence of the gas temperature on the progress of the 'cool flame' reactions. Their results also showed a close correlation between knock intensity and the gas temperature. Lucht et al |10] have used Coherent AntiRaman Stokes Scattering (CARS) to measure the unburned gas temperatures in knocking and non-knocking cycles. Their results showed little difference in the unburned gas temperatures for knocking and non-knocking cycles and they proposed that the cylinder pressure must be the controlling factor. However. in a companion paper, Ferguson [11] noted that if the autoignition chemistry was highly temperature dependent. temperature differences too small to be resolved by their measurements could be responsible for initiating atuoignition. This was shown to be the case by Hoffman ef a) $|12|$ who used 2 D-LIF to investigate hot spots in the unburned gas and concluded that temperature increases as small as 20 to $30 \mathrm{~K}$ were sufficient to initiate autoignition. Nakada 'f al $|13|$ showed that residual gases could increase the unbumed gas temperature by $55 \mathrm{~K}$ and for this reason proposed that their presence may promote knock. In their study of the cyclic variability of knock, Kalghatgi et al [14] noted that knocking cycles had higher end-gas temperatures than non knocking cycles although statistically reliable quantitative analysis was not possible due to the scatter in the results. These observations indicate that the likelihood of ETCS developing and promoting antoignition leading to knock are strongly dependent on the temperature history of the end-gas.

ETCs can be the result of inhomogencitics in the concentrations of the air. fucl and residuals that comprise the end-gas and especially the localised themal state of such inhomogeneities. They form where conditions are most favourable for accelerating the 'cool lame' chemistry [12].13],|15],|16|. The occurrence of these lavourable conditions appears essentially random but is more likely to occur under certain engine operating conditions and at certain locations in the end-gas. As a result, knock events are often not repeatable i.c. for a given engine opcrating condition. knock is unlikely to occur in every cycle and those cycles which do knock seem to have unique characteristics. Chun et al [17] noted this cyclic variability in the onset of knock and concluded that knock occurred in the faster buming cycles Bradley et al [18] investigated this in detai] and found that there is severe cyclic dispersion in the characteristics of knocking cycles. They were able to simulancously record cylinder pressure and the time of flame arrival at a point in the cylinder and concluded that the dispersion was a result of variability in the flame speeds giving rise to changes in the rate of compression of the end-gas which in turn affected its temperature history

To summarise. the work detailed in the literature reviewed above indicates that the primary factor influencing the onset of knock is the thermal state of the end-gas. Autoignition is initiated at ETCs where inhomogencities result in preferential conditions for the cool flame chemistry. The manner in which the combustion proceds from these ETCs is dependent on the temperature gradient at such locations and can be in either developing detonation or deflagration modes. or a combination of both.

In this paper. an existing quasi-dimensional cngine model [19].|20| has been modified $\mid 21] .122 \mid$ by discretising the endgas in order to cnable more accurate representations of the temperature field to be oblained especially near to the combustion chamber surfaces This has been coupled with a reduced chemical kinctic model for the pre-flame reactions of mixtures of air and iso-octane [23|. The combined model predicts the onset of autoignition and is used 10 investigate the effect of the flame propagation rate on the onset of autoignition. Prior to this howerer. we review cxisting chemical kinetic models of atoignition. their tuilisation in modelling work and discuss improvements offered by this work. Validation of the engine cycle simulation is afforded by comparisons of predicted temperatures and pressures with appropriate measured values for knocking and non-knocking cycles. Finally. cyclic variability in the onset of knock is simulated and the correlation between flame speed and the onset of knock is investigated. 


\section{KNOCK PREDICTION}

Several models for the prediction of engine knock are in cxistence. All have two essential components: viz. a chemical kinctic model and a means of evaluating the thermal state of the end-gas.

Chemical kinetic models for the combustion of the heavier hydrocarbons are very complex as hundreds of sub-reactions involving many tens of intermediate species that make up the combustion process have to be accounted for. These schemes have been developed over a period of time based on a fundamental understanding of the chemical mechanisms involved and are typically validated by comparison of computed ignition delays with those measured in rapid compression machines e.g. [24]. Kinetic modelling of combustion in engines however is further complicated by the complex fluid motion, thermal and compositional inhomogeneities and the large range of temperatures and pressures experienced by the end-gases.

t is necessary to use complex kinetic models when the focus of investigation is on the precise nature of the chemistry of the reactions involved. Leppard [25] used an existing, comprehensive chemical kinetic model to simulate autoignition and was able to predict the onset of knock well for the cases studied and identified the chemical mechanisms responsible. Moses et al [26] developed a very complex kinctic model based on the work of Westbrook and coworkers [27].[28] and used it to predict parametric trends in the knocking behaviour of engines using fuels containing methanol as an anti-knock. They were able to identify the reactions responsible for inhibiting knock during combustion with the mixed fuel. Westbrook et al [29] also used a complex kinetic model in a study of pro-knock and antiknock fucl additives. In contrast to the complex models afforded by detailed modelling of the combustion chemistry, workers at Shell Research in Thornton [30], [31], [32] developed a quasi-chemical knock model involving a small number of generic reactions. Their model was calibrated against engine data and was used to investigate trends in the effects of engine operating parameters on the onset of knock. This type of model is limited in that it does not represent the detailed chemistry of the combustion process and requires calibration against engine data. It has the advantage however that it can. once calibrated, predict some of the essential features of the pre-flame reactions (such as the approximate heat relcase rate). Griffiths et al [33] recently validated such a model for predicting autoignition with a CFD simulation of the gas in a rapid compression machine. Bradley et al [18] have also applied this model to evaluations of the onset of attoignition in an engine with reasonable success.

In an effort to overcome the limited range of applicability of the quasi-chemical type models and the high computational burden associated with the solution of detailed chemical kinetic mechanisms, simplified, or 'reduced' chemical kinetic models have been developed. These models account for the important, rate-limiting reactions by 'lumping' similar reactions from the detailed mechanism into groups. Hu and
Keck [34] developed such a model for the autoignition of mixtures of air, fuel and diluents and validated it against data from combustion bomb experiments. Chun of a/ $|17|$ used Hu and Keck's model |34] to predict knock occurrence in a spark ignition engine. Their simulated ignition times showed good agreement with measured ones except when knock occurred late in the cycle. They attributcd this to crrors in the calculation of the end-gas temperature at these times duc to the presence of thermal boundary layers. Brissovansky et al $[35]$ used a more sophisticated method for the calculation of the end-gas temperature and were able to use the reduced model $\mid 17],[34 \mid$ to predict certain parametric trends in the onset of knock with greater accuracy. Nakano et al $|36|$ employed a reduced kinctic model very similar to Hu and Keck's [34] to investigate the knock limited torque limit of engines. These works collectively show that reduced models are able to predict the onset of knock for single component fuels $[17],[34], \mid 35],[36]$ and. when calibrated. research grade gasoline and mixtures of primary reference fucls |36|. They also enable investigations to be made into the mechanisms of the combustion reactions since they compute the concentrations of certain key species involved in the rate controlling reactions $[35]$.

A kinetic model for the prediction of knock within the framework of a quasi-dimensional engine model is required. Cowart et al [37] have compared the performance of $\mathrm{Hu}$ and Keck's reduced kinetic model $[34]$ with an existing comprehensive kinetic model. They concluded that once calibrated, the reduced model was capable of predicting the onsel of knock with reasonable accuracy. The comprehensive model achieved the same result with no need for calibration but was computationally considerably more demanding. In view of this, Li et al's $|23|$ development of the model due to $\mathrm{Hu}$ and Keck $|17|$ is used in this study. They tuned the model to improve on the prediction of the heat release rate and $\mathrm{CO}$ emissions $|38|$ using experimental data for the autoigniton of n-heptanc. iso-octane and $87 \mathrm{PRF}$ in a 'motored' engine [39]. For the purposes of this work, a reduced scheme is more than adequate as we are not primarily interested in the precise details pertaining to the complex combustion chemistry. Rather. the focus of attention is on the heat release rate due to the pre-flame reactions and the onset of knock.

The kinetics of the combustion of hydrocarbon and air mixtures have been shown to be highly temperature dependent. The problem is further complicated by the fact that the reactions are cxothermic and the lical released can significantly affect the temperature of the end-gas $[11],[14], \mid 36], \mid 40]$. As a result, the thermal state of the endgas is closely coupled with the rate of the pre-flame reactions. When predicting knock. it is essential that the endgas temperature is accurately cvaluated. In the majority of cases, this has been achieved by computations from measured cylinder pressure data using techniques similar to those due to Chun and Heywood [41]. Additional accuracy is afforded by dividing the chamber into two \%ones. one comprising the unburned gas and onc comprising the burned gas

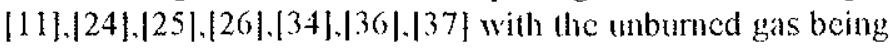


assumed to be at a uniform temperature. This type of analysis is limited since it neglects the temperature variations that are known to exist in this charge and especially the thermal boundary layers adjacent to the cylinder walls [42]. When the end-gas region is large, computations based on a uniform temperature in the end-gas will result in an underprediction of peak temperatures since heat transfer is accounted for in a global manner whereas, in reality, heat will be lost primarily from the gas near to the cylinder walls lcaving an almost adiabatic core. When the end-gas is almost lotally consumed, only the near-wall boundary layer regions remain and the temperature is likely to be over-predicted [17]. Ferguson et al [11] improved on this by developing algebraic expressions for computing the end-gas core tcmpcrature from cylinder pressure data accounting for the temperature gradients in the thermal boundary layer whilst Brussovansky et al $[35 \mid$ considered the centres of turbulent eddies as small adiabatic 'pockets' and were able to improve on predictions of knock onset with $\mathrm{Hu}$ and Keck's model $134 \mid$

As well as those models which essentially analyse measured data, knock models exist where the state of the cylinder gas is compuled withoul prior knowledge of the pressure. Griffiths et al $|3.3|$ predicted the pressure and end-gas tenuperatures for rapid compression with the computational fluid dynamics (CFD) code KIVA. Their predicted pressures agreed well with measured ones but their temperature predictions were not validated. Also, the fluid motion and the gas state in a rapid compression machine are considerably less complex than in the cylinders of IC engines. Moses et al [26] predicted knock in an SI engine with a model which simulancously computed the cylinder pressure. They validated the predicted pressures by comparing them with pressurc crank angle diagrams recorded during non-knocking operation of a spark ignition engine and reasonable

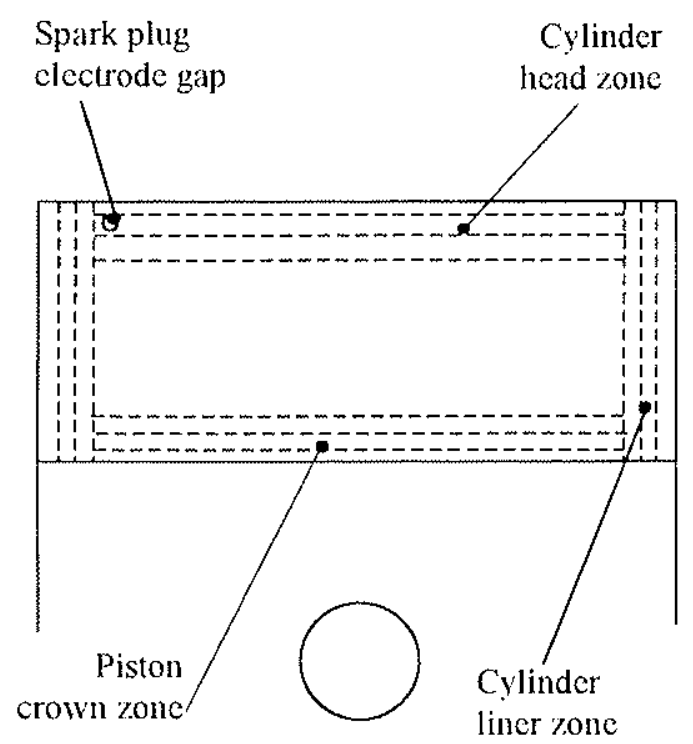

a. agreement was achieved over the combustion period. The engine model was semi-predictive as calibration based on empirical observation was required to establish the effect of turbulence on the mame speed. Such models have the advantage that they can be used to simulate parametric trends in the knock characteristics of engines without having to make pressure measurements.

\section{ENGINE CYCLE MODELLING}

An existing quasi-dimensional model $\mid 19] .|20|$ has been modified in order to accomt for the temperature gradients in both the burnt and unburnt gas thermal boundary layers near to the cylinder walls. Details of the program operation and solution lechniques have been published elscwhere $\{22 \mid$. Only the essentials are outlined here. The near-wall temperature gradients are accounted for by dividing the unburned gas into zones adjacent to the cylinder head. piston crown and the cylinder liner respectively. These surround a homogeneous. essentially adiabatic core region. Each of the near-wall zones is divided into a number of smaller masses (usually between 6 and 25 ) which are assumed to remait? 'stacked' in layers adjacent to their respective surfaces [21] (Fig. 1a). The flame is assumed to propagate spherically from a kernel initiated at the centre of the spark plug electrode gap. As the flame proceeds through the unburned gas, 'segments' of burned gases are produced (Fig. 1b). Mass elements, each with unique properties. are maintained adjacent to the cylinder walls in both the new burned gas segments and also the remaining unburnt gas segments cnabling the boundary layer behaviour all all locations to be modelled in the burned and unburned charge. In this way. multiple elcments are produced in both the burnt and unburnt charge, each wilh its own unique temperature. Validation of the ensuing thermal boundary layers has been achicved by comparison with measurements made by Lucht at al [42].

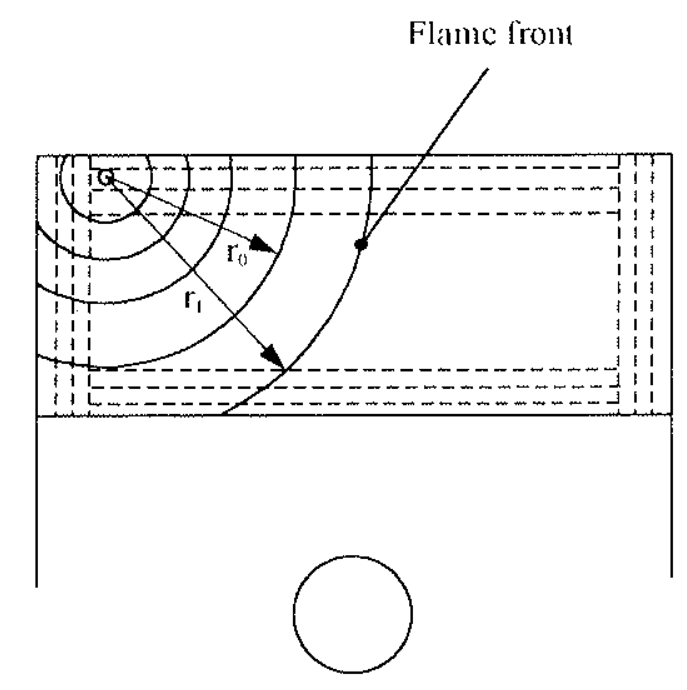

b.

Fig. 1 Typical layout of mass elements before ignition for an arbitary point during the combustion process. 


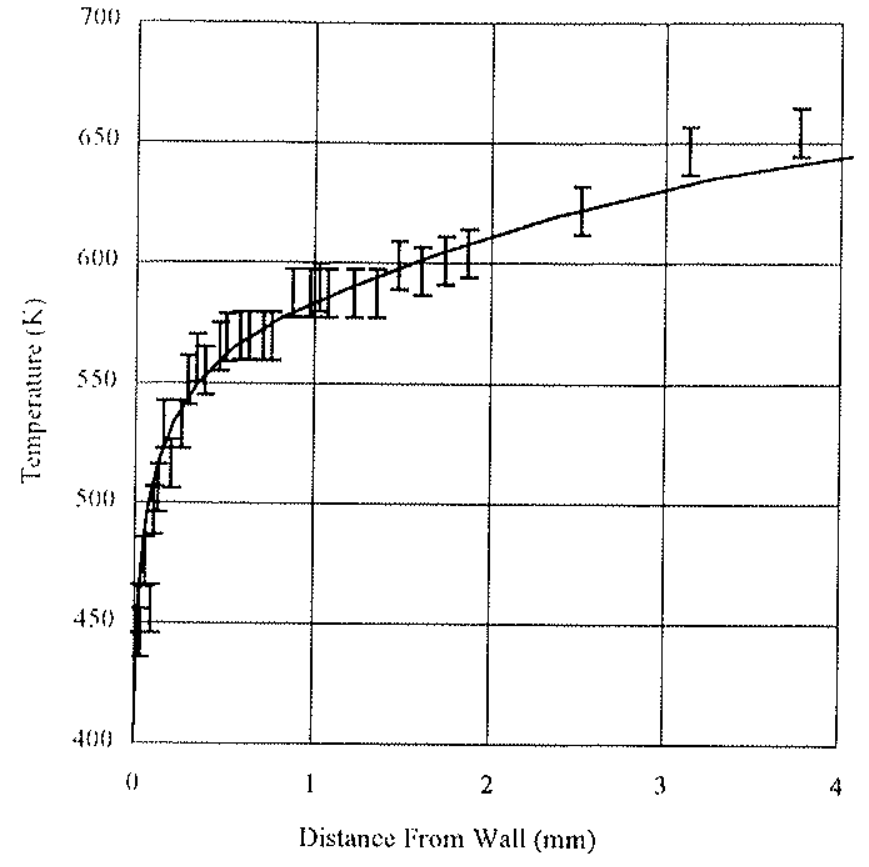

Fig. 2 Predicted and measured [42] near-wall temperatures in a motored engine at TDC.

(Symbols show measured data)

Fig. 2 and Fig. 3 are examples of this in the unburnt and burnt charge respectively. Further details of this validation can be found in references [21],[22].

The engine cycle model is fundamentally of the thermodynamic type so that spatially dependent phenomena such as the convection of enthalpy cannot be accounted for. In order to resolve the heat transfer between adjacent mass elements, a one-dimensional, control volume mesh for the solution of a discretised form of the conservation of energy equation is superimposed on the system of masses (Fig. 4). Up to 25 nodes can be accommodated in each thermal boundary hayer region but adequate resolution was found to be achicved with 10 nodes at these locations. New remperature profiles coinciding with the end of each calculation step are found using an cxplicit solution technique. The equation

$q_{i} \approx\left|\overline{C_{p}}\left(T_{p}-T_{p 0}\right)\right|_{\left(v_{i}\right.}-\left(P-P_{0}\right) v_{C v_{i}}-S_{h} \Delta t v_{C V_{i}}$

is tised to compute the specific energy change. \% in mass element i due to heat transfer arising from the new tempcratures obtained with the boundary layer model. Local gas wall interface heat fluxes are found using a discretised form of Fouricr's Law

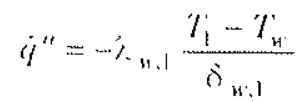

Comprehensive details of the techniques used can be found elscwhere 1211. The laminar burning velocity of iso-octane is computed using the method developed by James [43].

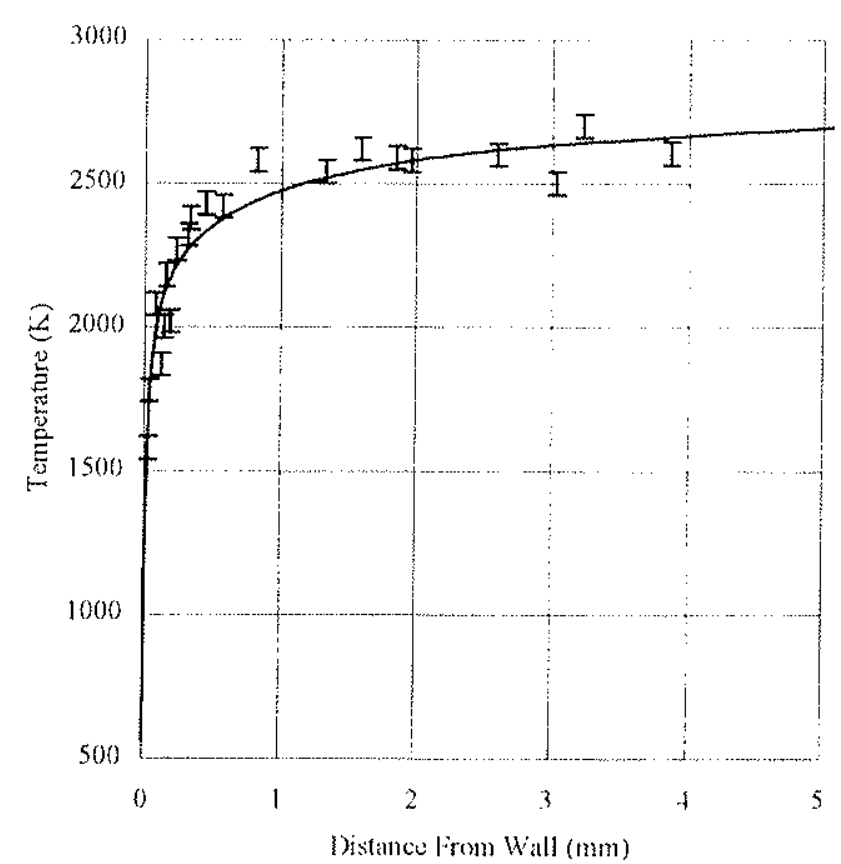

Fig. 3 Predicted and measured $|42|$ near-wall temporatures in burned gases at $375 \mathrm{CAD}$.

(Symbols show measured data)

Firstly, the laminar burning velocity at atmospheric pressure. $u_{11}$, is calculated as a function of the equivalence ratio, $\phi$. from a curve fit to Heimel and Weist s cxperimental data [44] measured at $\mathrm{I}$ atm and $599 \mathrm{~K}$. Corrections for evaluations at other unburned gas temperatures are made using a modified form of Lancaster et al's $|+5|$ cxtrapolation formula

$\left(\frac{u_{n 1}}{u_{12}}\right)=\left(\frac{T_{u 1}}{T_{n 2}}\right)\left(\frac{T_{m 1}}{T_{m 2}}\right)^{1 / 2} \operatorname{cxp}-\left[\left(\frac{E}{2 R}\right)\left(\frac{1}{T_{m 1}}-\frac{1}{T_{m 2}}\right)\right]$

where $T_{m}=T_{u}+0.76\left(T_{1}-T_{u}\right)$. The effects of diluents are accounted for with an cxpression duc to Mclaghalchi and

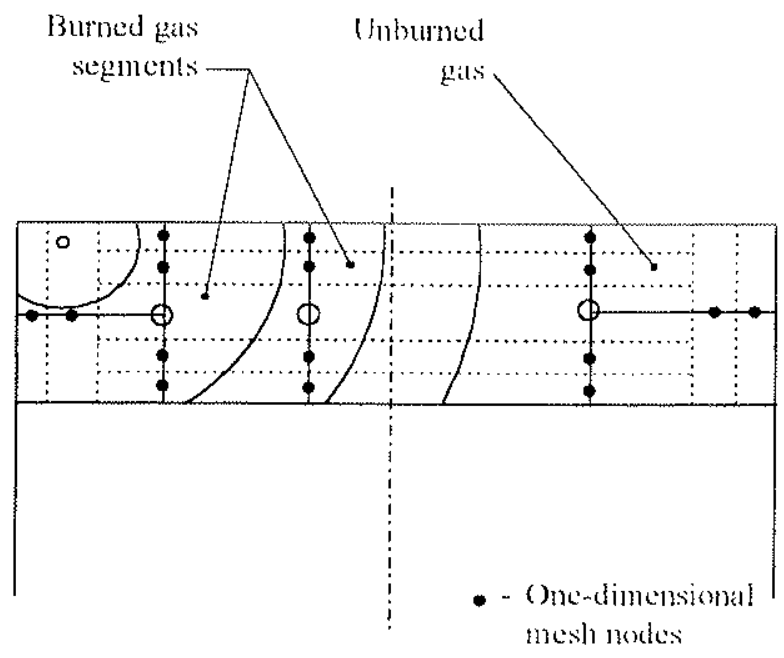

Fig 4. Superposition of one-dimensional finite volume mesh and system of discreet masses. 
Keck $|+6|$. Finally, $u_{1}$ is corrected for pressure differences (43) with the Cormula $u_{l(P)}=u_{l}\left(P / P_{0}\right)^{n}$ where

$n=n(\phi)-0.21+0.0004 T_{n}$

and

$n(\phi)=\cdots 1.3+2.28 \phi-1.16 \phi^{2}$

for weak mixtures

$n(\phi)=-0.76+1.1 \phi-0.52 \phi^{2}$

for rich mixtures

A ractal lame model (FFM) is used to compute the turbulent burning velocity. Fractal analysis is a mathematical technique which can be used to quantify the perturbation of the flame shect by the in-cylinder turbulence [47]. A power law expression computes the turbulent burning velocity, $u_{\text {, }}$. from the laminar burning velocity, $u_{\text {, }}$ and the inner and outer cul-offs for the flame wrinkling scales. These are given in tcrms of maximum and minimum lengths, $l_{\max }$ and $l_{\min }$. resulting in the expression

$u_{t}=u_{1}\left(\frac{l_{\text {max }}}{l_{\text {man }}}\right)^{\left(b_{3}-2\right)}$

Fraclal dimensions, $D_{3}$, have been measured as $2.37 \pm 0.3$ for turbulent nows [48],[49],[50],[51]. Considering this, Chun et al $s|52|$ heuristic expression

$$
D_{*}=2.0\left(\frac{u_{1}}{u^{\prime}+u_{1}}\right)+2.37\left(\frac{u^{\prime}}{u^{\prime}+u_{l}}\right)
$$

is used. The inner cut-off, $l_{\min }$, has been observed to be 1.3 to 5.8 times the Kolmogorov length scale, $\ell_{k}$, [51], [53]. In this work. a value of $3.0 \ell_{k}$ has proved to be satisfactory. The outer cut-off. / max $_{\text {mas }}$ heen observed to be several times larger than the integral length scale. In the early stages of flame propagation. $l_{m a x}$ is limited by the flame size until it becomes constrained by the combustion chamber geometry. The piece-wise expression.

$$
\begin{array}{ll}
l_{\text {mic }}=r_{i} & 0<r_{i}<H \\
l_{n \rightarrow i x}=H & H<r_{r}
\end{array}
$$

is used here where $r_{f}$ is the flame radius and $H$ is the instantancous clearance height. When the flame is small, it is only going to experience the effects of the turbulent Muctuations with length scales smaller than its dimensions. Wu $"$ al $|5+|$ used energy cascade arguments to develop the expression

$$
\varepsilon=\frac{u^{2}}{r_{i}}=\frac{u_{t^{\prime} !}^{3}}{r_{i}}
$$

which was rearranged to give

$$
u_{m}^{\prime}=\left(\frac{r_{i}}{r}\right)^{1 / s} \quad 0<r_{i}<r_{i}
$$

for the calculation of the effective turbulence intensity cxperienced by the flame when it is small. Many empirical studies have shown that the in-cylinder turbulence becomes almost isotropic and homogencous as the compression stroke proceeds in both tumbling |55|.|56|.157| and swirling $[58] .159] .1601 .161 \mid$ flows. In such flows. the lurbulence kinetic cnergy, $k$. can be used to quantify the characteristic velocity of the turbulence. A bulk averaged $k-s$ : turbulence model has been developed in order to account for the general features of in-cylinder turbulence characteristics. Such models have been used many times elsewhere |62], [63].|64],|65|. If the in-cylinder turbulence is assumed to be homogeneous, all spatial derivatives become \%cro in the conservation equations for $k$ and $r$ so that the following equations apply:

$$
\frac{d(\rho k)}{d t}=G_{1 / k}-\rho
$$

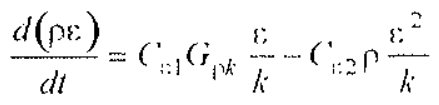

The production term for the turbulence kinctic energy. $i_{j}$. has been rearranged in order to scparate the terms that account for turbulence generation due to Mow dilation from the terms accounting for turbulence generation in regions of fluid shear to give

$$
G_{p k}=\frac{2}{3} k \frac{d \rho}{d t}+\tau i j \cdot \frac{d l_{i}}{d x_{j}} \quad \text { for } i \neq j
$$

The dilation term is casily computed as it involves the time derivative of densily a scalar property of the gas. However evaluation of the icrm for the turbulence generation as a result of how shcar necessitates a knowledgc of the mean velocity gradients. Several studies have shown that the mean velocity ficld approaches solid body rotation in swirling flows [66],[67]. Therefore. it can be assumed that very little turbulence is generated in the bulk gases of such flows. However. high velocity gradicnts exist in the momentum boundary layers adjacent to the cylinder walls $|68| .|69|$. Turbulence generation in these regions is accounted for with a simple boundary layer model. The model assumes a linear velocity profile across a momentum boundary layer with a thickness typical of those found from measurements $[68] .[70\}$. The Reynolds stresses near to the cylinder walls are assumed to be equal to the wall shear stress which is computed using skin friction theory 1711 and a knowledge of the langential velocity of the solid rotating body

The turbulence intensily is computed from $k$ according to the expression 


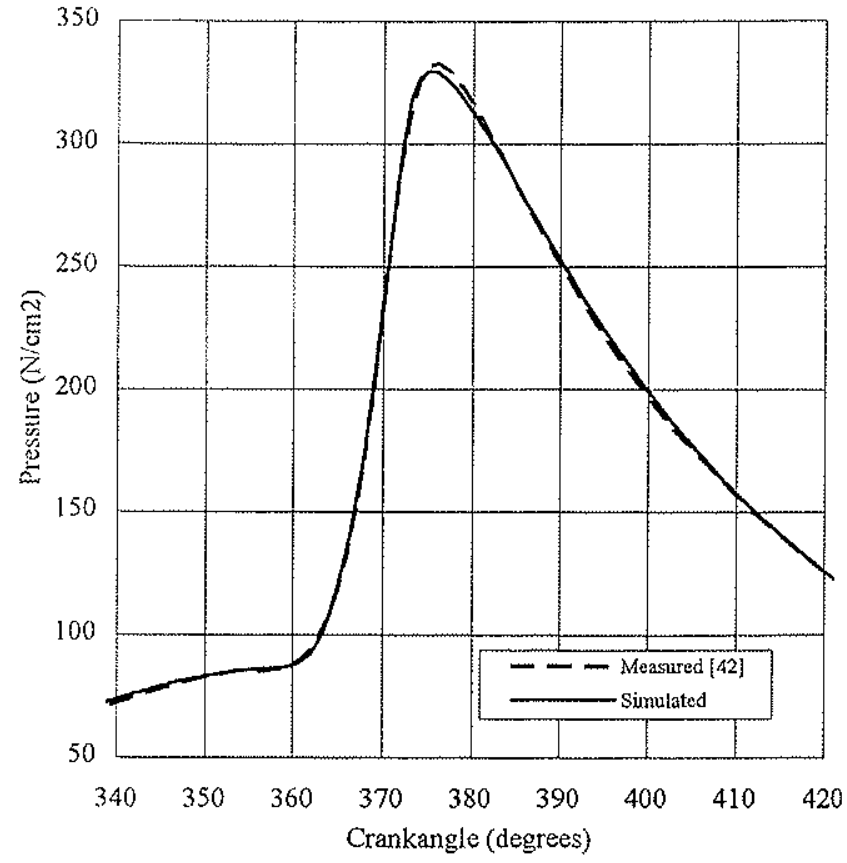

Fig. 5 Measured [42] and predicted cylinder pressures.

$$
u^{\prime}=\sqrt{\frac{2}{3}} k
$$

arising from the definition of the turbulence kinetic energy. This turbulence intensity provides the input for the FFM. The expression

$$
\mu_{t}=C_{\mu} \rho k^{3 / 2}
$$

is used to compute the eddy viscosity, $\mu_{t}$, from the conserved turbulence properties. Following this, the ratio of the turbulent eddy conductivity to the fluid thermal conductivity can be calculated according to:

$$
\frac{\lambda_{t}}{\lambda}=\frac{\mu_{t}}{\operatorname{Pr}} \frac{\operatorname{Pr}}{\mu}
$$

where $\operatorname{Pr}_{t}=1.0$ and $\operatorname{Pr}=0.7$

Comprehensive validation of the model in terms of pressurecrankangle diagrams and predicted gas temperatures and gaswall interface heat fluxes has been published elsewhere [22]. Fig. 5 shows a typical comparison between simulated pressures and those measured in the Sandia optical access research engine [72]. Table 1 summarises the operating conditions, engine specification and the associated empirical input for the engine cycle simulation. The simulated and measured results show good agreement. Fig. 6 compares predicted and measured turbulence intensities under motored conditions corresponding to the operating conditions in Table 1. Differences between the predicted and measured turbulence intensities are apparent. It is thought that this is due to the unusual flow field in the Sandia engine. The
Table 1: Sandia optical access research engine specification operating conditions and empirical input for simulations.

Engine specifications:

No, of cylinders 1

Bore $(\mathrm{cm})$

Stroke (cm)

Con. rod length $(\mathrm{cm})$

20.3

Crevice volume (cc)

3.0

Compression ratio

5.4

Combustion chamber shape

Pancake

Spark plug position

Central

IVC (CAD)

240.0

Operating conditions:

Speed (rpm.)

1200

Equivalence ratio

1.0

Throttle

Wide open

\section{Empirical imput:}

Residual mass fraction*

0.01

Turbulence generation (Swirl ratio) $\quad 4.75$

Wall temperature $(\mathrm{K})^{* *}$

$430 \mathrm{~K}$

Temperature at IVC $(\mathrm{K})$

Pressure at IVC (bars)

1.275

* Skip fired engine

** Estimated based on the value employed by Wu et al [54] when simulating this engine and measured by Lucht et al [42] in the engine with a modified cylinder head.

engine has very small valves mounted in the cylinder wall which induce high amounts of turbulence with a slight tumbling motion and very little swirl [72] during the induction process. The terms for the production of turbulence in regions of high shear in $\mathrm{EQ}$ (12) are only applicable to flows exhibiting solid body rotation. However, the general characteristics of the turbulence are reproduced even though there is divergence in terms of absolute

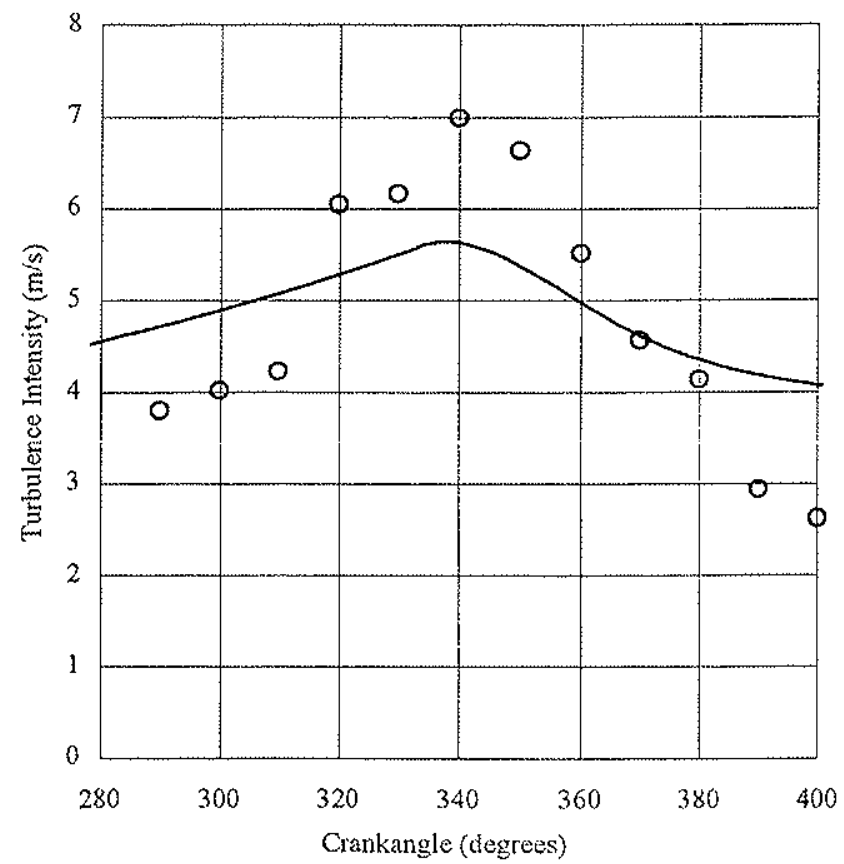

Fig. 6 Measured [42] and predicted turbulence intensities (Symbols show measured data) 


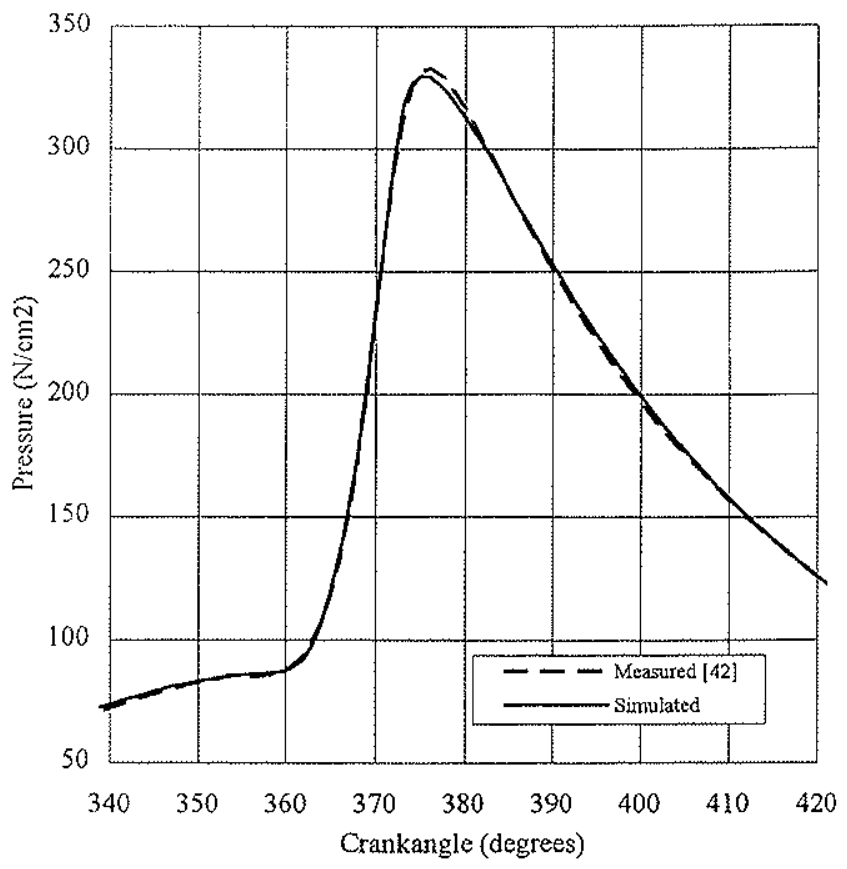

Fig. 5 Measured [42] and predicted cylinder pressures.

$$
u^{\prime}=\sqrt{\frac{2}{3}} k
$$

arising from the definition of the turbulence kinetic energy. This turbulence intensity provides the input for the FFM. The expression

$$
\mu_{t}=C_{\mu} \rho k^{3 / 2}
$$

is used to compute the eddy viscosity, $\mu_{t}$, from the conserved turbulence properties. Following this, the ratio of the turbulent eddy conductivity to the fluid thermal conductivity can be calculated according to:

$$
\frac{\lambda_{f}}{\lambda}=\frac{\mu_{t}}{\operatorname{Pr}} \frac{\operatorname{Pr}_{t}}{\mu}
$$

where $\mathrm{Pr}_{f}=1.0$ and $\mathrm{Pr}=0.7$.

Comprehensive validation of the model in terms of pressurecrankangle diagrams and predicted gas temperatures and gaswall interface heat fluxes has been published elsewhere [22]. Fig. 5 shows a typical comparison between simulated pressures and those measured in the Sandia optical access research engine [72]. Table 1 summarises the operating conditions, engine specification and the associated empirical input for the engine cycle simulation. The simulated and measured results show good agreement. Fig. 6 compares predicted and measured turbulence intensities under motored conditions corresponding to the operating conditions in Table 1. Differences between the predicted and measured turbulence intensities are apparent. It is thought that this is due to the unusual flow field in the Sandia engine. The
Table 1: Sandia optical access research engine specification. operating conditions and empirical input for simulations.

\section{Engine specifications:}

No. of cylinders

Bore $(\mathrm{cm})$

1

Stroke $(\mathrm{cm})$

Con. rod length $(\mathrm{cm})$

8.255

Crevice volume (cc)

20.3

Compression ratio

3.0

Combustion chamber shape

5.4

Spark plug position

Pancake

IVC (CAD)

Central

240.0

Operating conditions:

Speed (rpm.)

1200

Equivalence ratio

Throttle

1.0

Empirical input:

Residual mass fraction* $* 0.01$

Turbulence generation (Swirl ratio) $\quad 4.75$

Wall temperature $(\mathrm{K})^{* *} \quad 430 \mathrm{~K}$

Temperature at IVC (K) 340

Pressure at IVC (bars) $\quad 1.275$

* Skip fired engine

** Estimated based on the value employed by Wu et al [54] when simulating this engine and measured by Lucht et al [42] in the engine with a modified cylinder head.

engine has very small valves mounted in the cylinder wall which induce high amounts of turbulence with a slight tumbling motion and very little swirl [72] during the induction process. The terms for the production of turbulence in regions of high shear in EQ (12) are only applicable to flows exhibiting solid body rotation. However, the general characteristics of the turbulence are reproduced even though there is divergence in terms of absolute

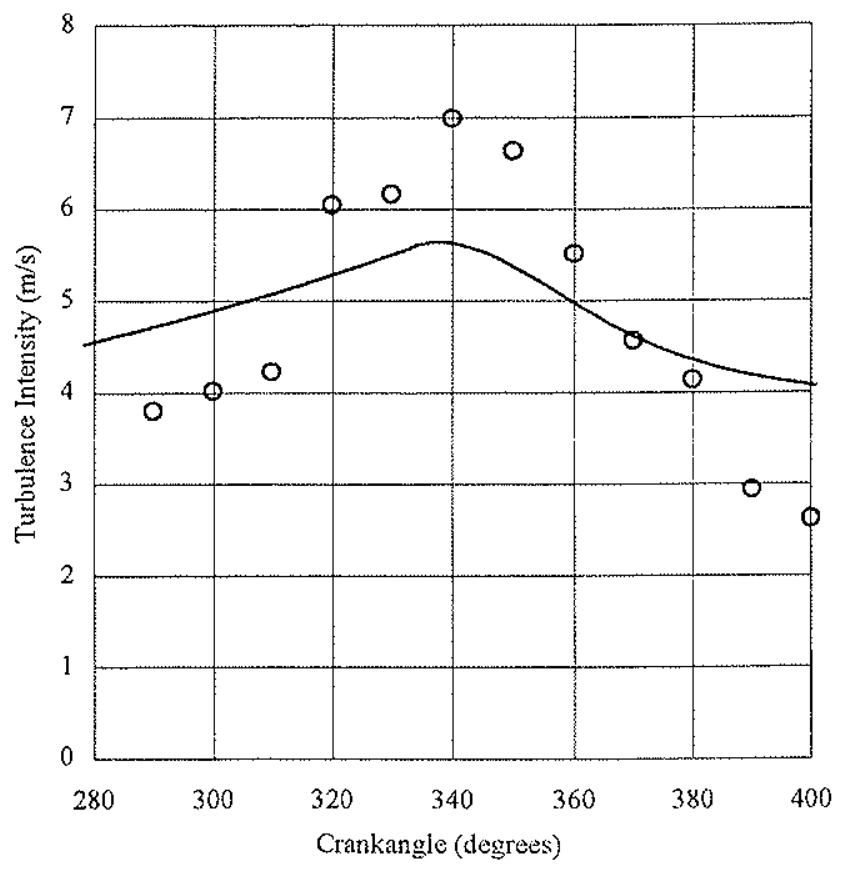

Fig. 6 Measured [42] and predicted turbulence intensities 77
(Symbols show measured data) 
magnitudes. The trend of increasing turbulence during the compression stroke and subsequent decay after 340 crankangle degrees (CAD) is reproduced and the maximum error is $17 \%$ which is acceptable here in view of the fact that the measured turbulence intensities are ensemble averages and thus include velocity fluctuations due to cyclic variability. No data for the gas-wall interface heat flux was available for this engine but heat fluxes are of the order of $0.3 \mathrm{MW} / \mathrm{m}^{2}$ towards the end of compression which is comparable to the maximum values measured in a motored engine with a pancake shaped combustion chamber at 1200 rpm by Dao [73]. Local heat fluxes in the burned gas peak at values between 1.1 and $1.4 \mathrm{MW} / \mathrm{m}^{2}$ which are also comparable with typical values measured in a fired engine by Alkidas [74]. In conclusion, the examples shown substantiate the model's ability to predict the gas state during compression, combustion and expansion with reasonable accuracy.

\section{COUPLING THE KINETIC MODEL AND THE ENGINE CYCLE SIMULATION}

As discussed in the preceding sections, studies have comprehensively shown that the rates of the pre-flame reactions are highly temperature dependent. Energy is released into the end-gas raising its temperature. This in turn increases the rate of the low temperature chemistry with consequent knock-on effects on the rate of heat release. It is apparent that the progress of the pre-flame reactions and the thermal state of the end-gas are closely coupled and it is essential therefore that this is reflected in any knock predicting engine simulation. Existing models have achieved this by integrating the conservation of energy equation. simultaneously with the equations for the rate of change of the reactive species in the chemical kinetic model (e.g. [17], [23],[26],[34],[35]). A different approach is necessitated here because the engine simulation does not employ integral methods. The compression, combustion and expansion processes are assumed to be quasi-steady and the equations for the overall system mass and energy along with equations for the entropy of the respective mass elements are iteratively solved to yield the cylinder pressure and mass element temperatures and composition for an instant in time. Details of this approach have been itemised elsewhere [19]. However, progress of the pre-flame reactions cannot be established in this way. Knock modelling poses an initial value problem which can only be solved by integration of the ordinary differential equations (ODEs) for the dependent variables from a set of initial conditions. Therefore, the only method available for the solution of such mathematical systems is the simultaneous integration of the ODEs for the rate of change of concentration of the participating species using computer routines specifically for the purpose. An additional equation has been added to account for the enthalpy released by the pre-flame reactions viz:

$$
\frac{d h_{i}}{d t}=\frac{\dot{h}_{i}^{\prime \prime \prime}}{\bar{\rho}_{i}}+\dot{q}_{i}+\dot{w}_{i}
$$

where $h_{i}$ is the specific enthalpy of element $i$. The volumetric heat release rate for element $i, \dot{h}_{i}^{\prime \prime \prime}$, is calculated from

$$
\dot{h}_{i}^{\prime \prime \prime}=\sum_{j=1, n} \dot{h}_{j}^{\prime \prime \prime}\left(R_{j}^{\dagger}-R_{j}^{-}\right) \quad j=1, n
$$

where $n$ is the number of reactions and $R_{j}^{+}$and $R_{j}^{-}$are the forward and backward rates of the $j$ th reaction given by

$$
R_{j}^{ \pm}=k_{j}^{ \pm} \prod_{k m 1}^{m}\left[N_{k}\right]^{v_{k}^{ \pm}}
$$

where $m$ is the number of reactive species. For a small time interval, $\Delta t$, the average rate of heat transfer per unit mass for element $i, \dot{q}_{i}$, can be calculated according to

$$
\dot{q}_{i}=\frac{q_{i}}{\Delta t}
$$

where $q_{j}$ is the total heat transfer per unit mass for element $i$ over the time interval $\Delta t$. The average rate of work per unit mass for element $\dot{i}, \dot{w}_{i}$, for a small time step, $\Delta t$, is computed using the equation

$$
\dot{w}_{i}=\frac{\left(P_{1}-P_{0}\right)}{\Delta t} \frac{1}{\bar{\rho}_{i}}
$$

where $\bar{\rho}_{i}$ is the average density of element $i$ during the period $\Delta t$. The ODEs for the rate of change of concentration of the reactive species are formed for each element $i$ in the manner given by Leppard [25]:

$$
\frac{d\left[N_{k}\right]_{i}}{d t}=R_{k_{i}}+\left[\dot{N}_{k}\right]_{i(P, T)} \quad k=1, m
$$

$R_{k_{i}}$ is the rate of change of species $k$ in element $i$ due to chemical reaction and the rate of change of the concentration of species $k$ in element $i$ due to temperature and pressure changes, $\left[\dot{N}_{k}\right]_{i(P, T)}$, is given by:

$$
\left[\dot{N}_{k}\right]_{i(P, T)}=-\left[N_{k}\right]_{i}\left[\frac{1}{T_{i}} \frac{d T_{i}}{d t}-\frac{1}{P} \frac{d P}{d t}+\frac{1}{[N]_{T_{i}}} \frac{d\left[N_{T}\right]_{i}}{d t}\right]
$$

$\mathrm{EQ}(22)$ is integrated over a finite time, $\Delta t$, and then divided by $\Delta t$ to yield

$$
\begin{aligned}
& {\overline{\left[\dot{N}_{k}\right]_{i(P, T)}}}=-\overline{\left[N_{k}\right]_{i}}\left[\frac{1}{\bar{T}_{i}} \frac{\left(T_{1}-T_{l_{\text {otd }}}\right)_{i}}{\Delta t}-\frac{1}{\bar{P}} \frac{\left(P_{1}-P_{i_{\text {oLD }}}\right)}{\Delta t}\right. \\
& \left.+\frac{1}{\left[N_{T}\right]_{i}} \frac{\left(\left[N_{T}\right]_{1}-\left[N_{T}\right]_{l_{O L D}}\right)_{i}}{\Delta t}\right]
\end{aligned}
$$




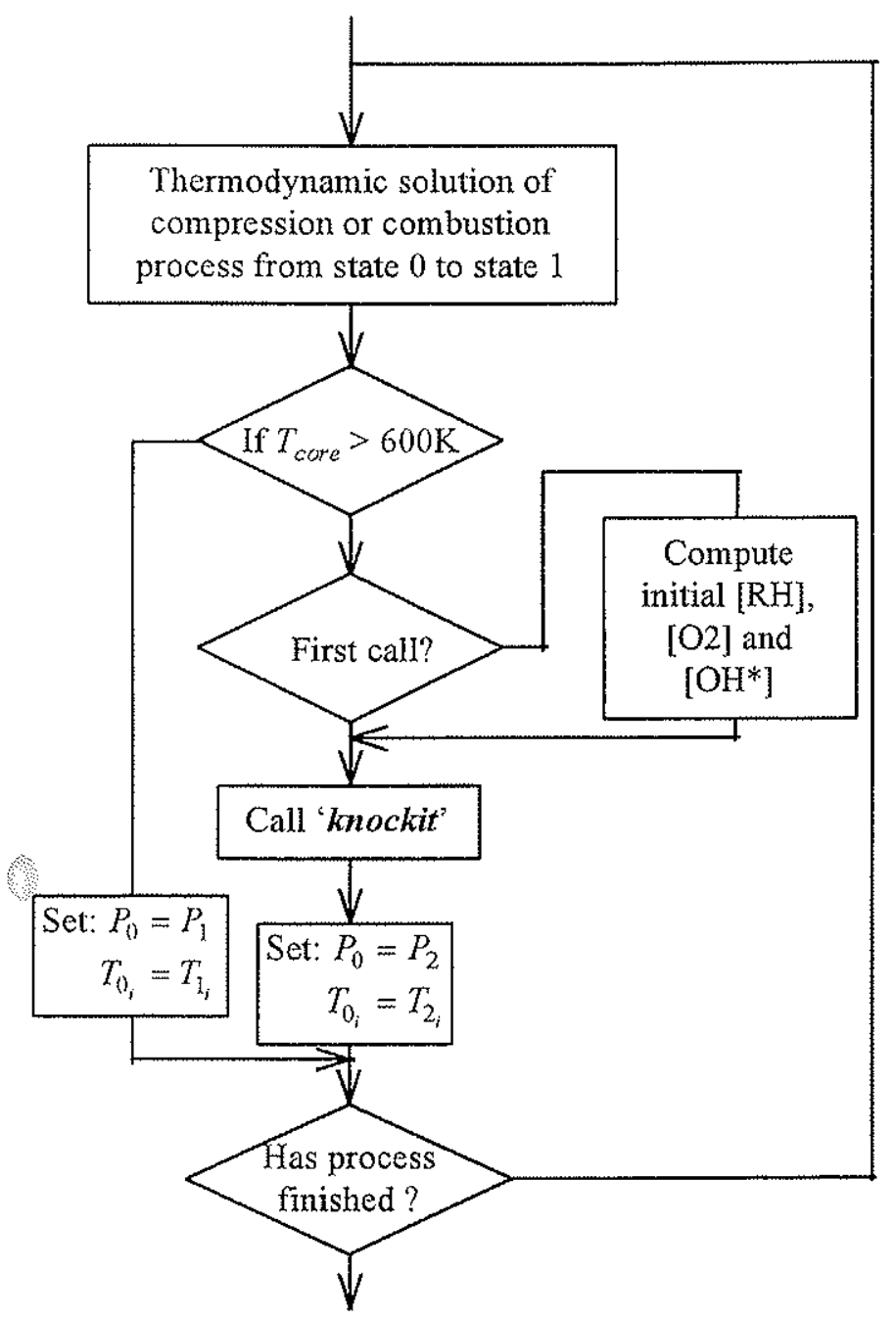

Fig. 7 Flow chart showing the integration of the thermodynamic solution and the kinetic model.

$\bar{T}_{i}$ is the average temperature of element $i$ and $\bar{P}$ is the average pressure during the interval $\Delta t$. The average total molar concentration for each element over the time interval $\left.\Delta t, \overline{[N}_{T}\right]_{i}$, is obtained from the ideal gas law according to:

${\overline{\left[N_{T}\right]_{i}}}_{i}=\frac{\bar{P}}{\widetilde{R} \bar{T}_{i}}$

and the total molar concentrations at state 1 and state 1 (old) in the computational procedure are found in a similar manner. This method has been found to accurately account for the change in species concentration due to changes in the mixture density as a result of changes in the gas temperature and pressure as well as the chemical reactions.

Fig. 7 shows a schematic of the interaction between the chemical kinetic model (contained in subroutine 'knockit') and the overall engine simulation. During the compression or combustion processes, once the unburned gas exceeds a minimum temperature below which the pre-flame reactions are assumed to occur so slowly that they are effectively 'frozen' $(600 \mathrm{~K})$, initial conditions for the molar concentrations of the air and fuel are based on the operating conditions (e.g. the mass fraction of residuals, fuel type and air/fuel ratio). Additionally, the initial molar concentration of $\mathrm{OH}^{*}$ is computed from the values given by the chemical equilibrium subroutines for the calculation of the residual gas composition in the main program. Following this, the subroutine knockit (Fig. 8) is called. Knockit integrates the ODEs for the rate of change of species and enthalpy over a time interval equal to the calculation step. Work and heat transfer are computed using EQ (20) and EQ (19) respectively from the temperatures and pressure at state one in the preceding calculation step and the current state one temperatures and pressure (Fig. 8). The new species concentrations and temperatures and pressure at state 2 (taking into account the heat released by the pre-flame reactions) are then yielded. The newly computed temperatures and pressure are returned to the main program where they form the initial conditions in the solution of the thermodynamic model over the next calculation step. It is assumed that once the gas has attained the minimum $600 \mathrm{~K}$

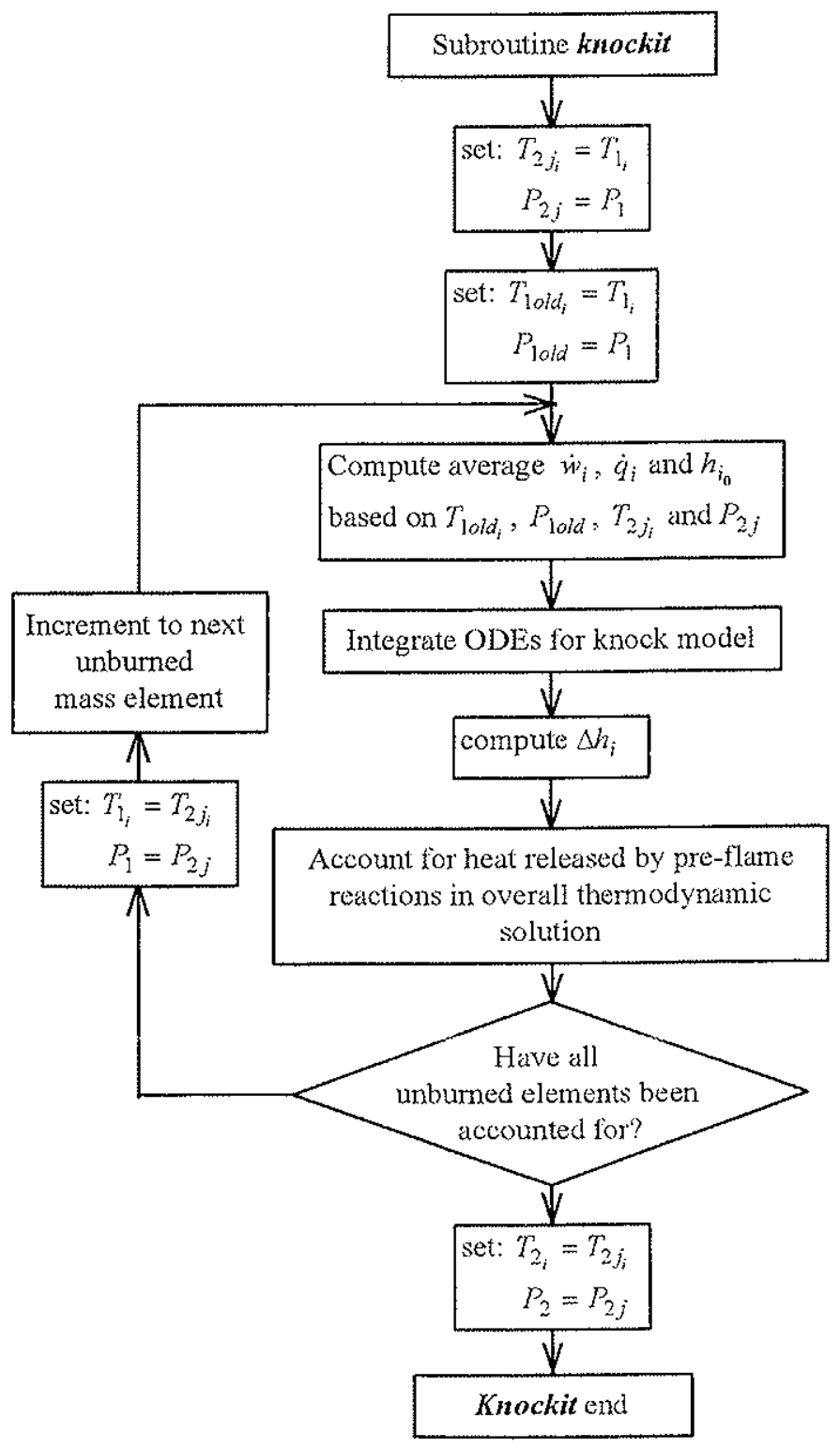

Fig. 8 Flow chart of the key steps in knockit. 


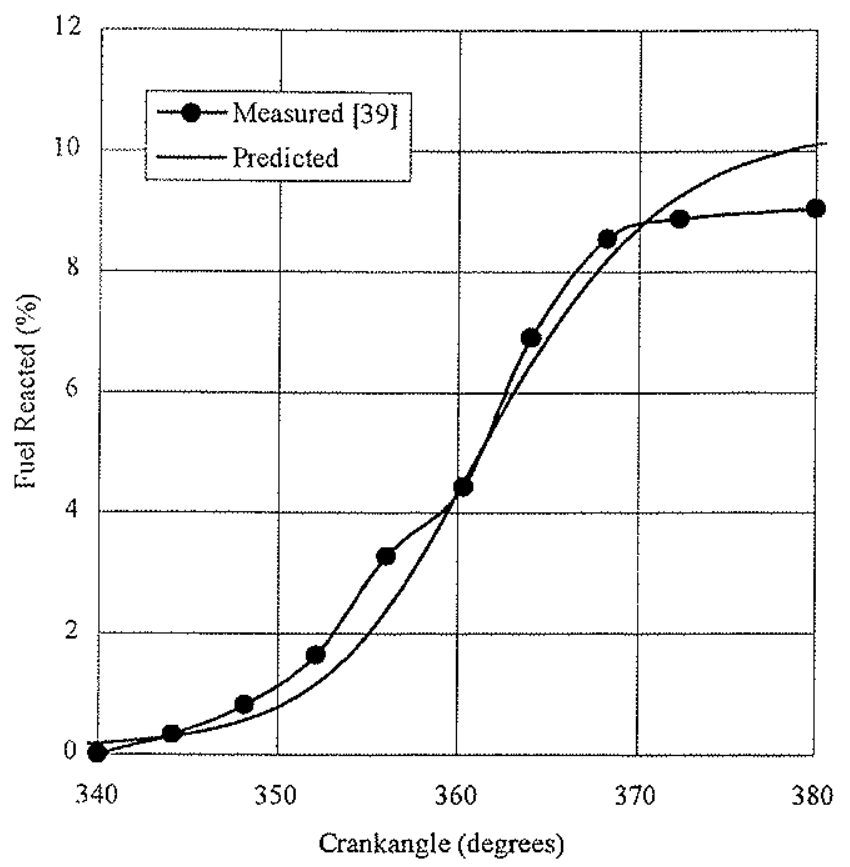

Fig. 9 Measured [39] and predicted cumulative fuel reacted in a motored engine.

temperature, compression by the ascending piston or the propagating flame front and heat released by the pre-flame reactions will invariably result in a continuing increase in the unburned gas temperatures during the delay period. As a result, knockit is called for all successive calculation intervals once the critical temperature has been attained. The values for the concentrations of the reactive species computed during the previous invocation of the subroutine knockit are used as the initial conditions for the next time step.

Validation of the combined model is afforded by reproducing the results presented by $\mathrm{Li}$ et al [23] who used the knock model to simulate the first stage ignition of mixtures of isooctane, air and residuals in a non-fired engine. The engine was motored at $1200 \mathrm{rpm}$ and had a compression ratio of 8.2 . Gas samples were collected using rapid sampling valves [39]. The engine was a modified version [75] of the Sandia optical access research engine detailed in Table 1 for which, with a different cylinder head arrangement but the same valve set, the thermal boundary layer predictions obtained with the thermodynamic model have been validated (Fig. 2 and Fig. 3 ). On this basis the thermodynamic model is capable of reproducing the temperature field for the operational build employed by Li et al [39]. A wall temperature of $400 \mathrm{~K}$ was used. This has been estimated from the near wall temperature profiles due to Lucht et al [42] measured in the Sandia optical access research engine during motored operation. Under these conditions, only the gas in the essentially adiabatic core (Fig. 1) showed significant reactivity. The near-wall mass elements did not attain sufficiently high temperatures to initiate the first stage of ignition. The cumulative fuel consumption (or \% fuel reacted) for a mixture of iso-octane and air with a residual mass fraction of $13 \%$ and an inlet air temperature of $376 \mathrm{~K}$ was computed to compare with measurements presented by Li et $\alpha$ in [39] under the same conditions. Results from this exercise are shown in Fig. 9. Good agreement is afforded. Fig. 10 compares predicted core gas temperatures for the simulation corresponding to the fuel consumption data in Fig. 9 with predicted results for the same conditions in which the heat release due to the low temperature chemistry has been ignored. The inclusion of the effects of the pre-flame reactions caused a predicted temperature rise in the core region of approximately $18 \mathrm{~K}$ agreeing with Li et al [23]. The gas temperature in Fig. 10 for the case where the low temperature chemistry has been incorporated does not exhibit the rapid rise commonly associated with autoignition because only first stage ignition occurred for the mixture of iso-octane and air under the conditions tested.

It can be concluded from the results in Fig. 9 that the new coupled kinetic and thermodynamic engine cycle model can be employed to predict the rate of pre-flame reactions during the first stage of ignition with reasonable accuracy since the fuel reacted was measured under the same conditions and is accurately reproduced. The results in Fig. 10 indicate that the combined model is also able to account for the energy released by the pre-flame reactions in the overall thermodynamic analysis of the system affording validation to the techniques employed.

\section{PREDICTING THE ONSET OF KNOCK IN A FIRED ENGINE}

A thermodynamic analysis of engine cycles using the type of computer model developed here can only be achieved if the system is assumed to be quasi-steady or, in other words, if the gas pressure is taken to be uniform throughout the entire cylinder. Simultaneous measurements of the cylinder

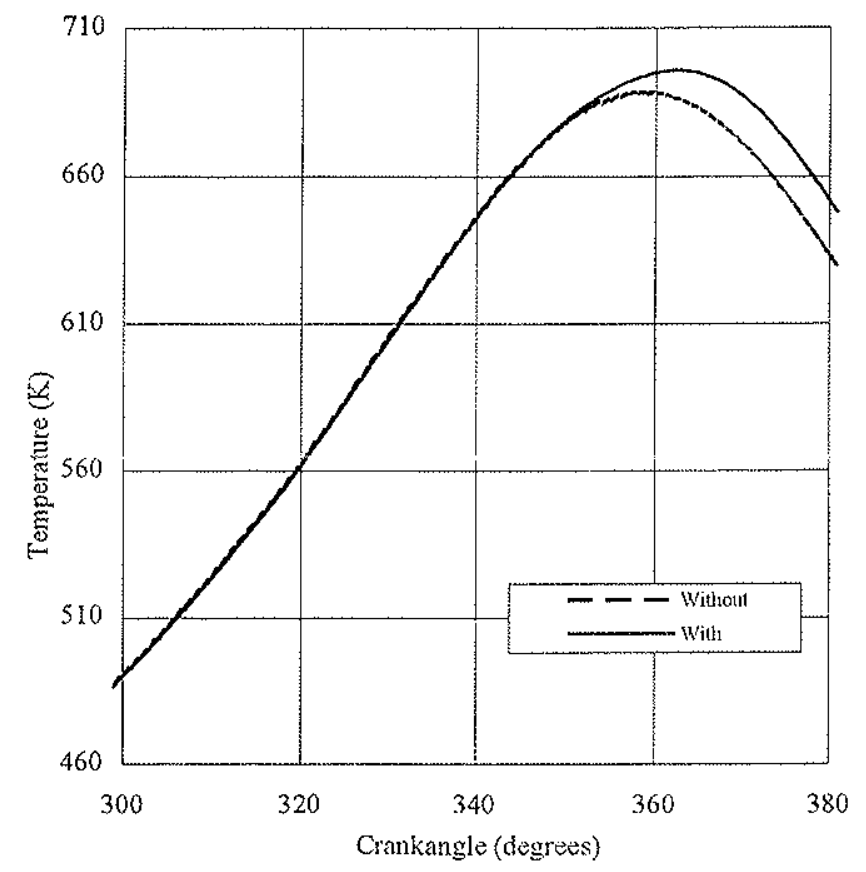

Fig. 10 Predicted core gas temperatures with and without pre-flame reactions. 


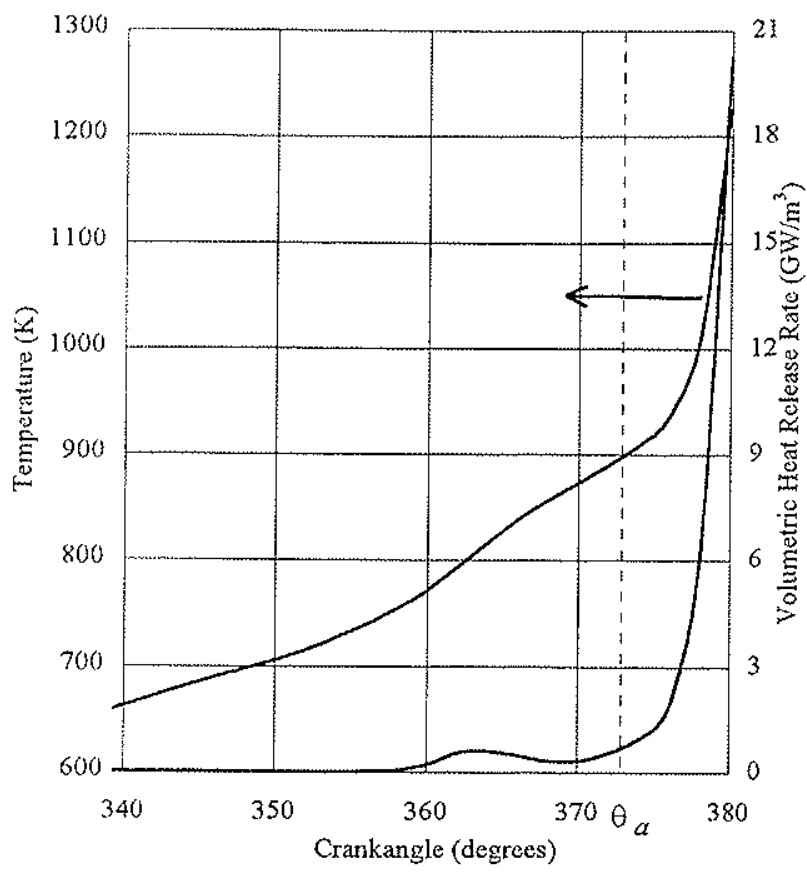

Fig. 11 Predicted end-gas temperature and volumetric heat release rate showing the point of autoignition.

pressure have been made with multiple pressure transducers by Witze and Green [76] during knocking operation of the Sandia optical access research engine. Considerable differences in the instantaneous values of the measured pressures and the nature of the acoustic oscillations were noted at different points in the combustion chamber. This conclusively demonstrates that the cylinder pressure in not uniform after the onset of knock and our thermodynamic model cannot thus be employed after this point. Kalghatgi et al [77] used a heat release analysis similar to Chun and Heywood's [41] to compute the overall heat release rate from pressure-crankangle diagrams obtained from a knocking engine. They noted that knock occurred very close to the instant of maximum heat release rate. This trend was also monitored by Bradley et al [78] who developed a more $\Delta$ omprehensive three zone model employing a one-step Arrhenius function that was first order with respect to the fuel concentration to account for the heat release rate (HRR) by the pre-flame reactions. The onset of autoignition was defined in both studies $([77],[78])$ as the instant when the volumetric heat release rate profile showed a rapid increase (as is shown in the illustrative example in Fig. 11). Results presented by Bradley [78] showed that the volumetric HRR rapidly increased after an initial period where the rate of increase was small. Once this point was attained, the maximum value corresponding to the onset of knock was attained 2 or $3 \mathrm{CAD}$ later (Fig. 11). From this, it can be concluded that the quasi-steady assumption remains applicable at the onset of autoignition and during the early stages of the rapid heat release phase. Therefore, a thermodynamic analysis of the end-gas coupled with a kinetic model for the low temperature ignition chemistry in this region can be applied during the early stages of the autoignition/knock process. In this respect, a computer model of the type developed here is able to provide useful information regarding the knock onset time (KOT) and the HRR during the early stages of autoignition.

Theoretical studies [8],[78] have demonstrated that knock is the result of interactions between one or more ETCs in the end-gas and the acoustic waves set up by local overpressures due to high volumetric heat release rates in these regions [78]. Therefore, an exact determination of the precise point in the cycle where knock first manifests itself is extremely difficult. Kalghatgi et al [14] have noted that the sequence of events leading up to the points of maximum knock intensity in cycles with different knock onset pressures show different characteristics. In their studies, they have overcome any ambiguities in the definition of the KOT by filtering the measured pressure histories and ignoring oscillations with amplitudes below 0.2 bar. The KOT is then defined as the point where the first oscillation exceeds this value. Other researchers [17], [35], [37] have analysed the rate of change of pressure in order to define the KOT. For example, Chun et al [17] defined the KOT as the instant when $P / \dot{P}$ exceeded 0.2 ms while Brussovansky et al [35] defined the KOT as the point in the cycle where $d P / d \ominus$ exceeded $2.8 \mathrm{~atm} / \mathrm{degCA}$.

Defining the KOT when simulating the events leading to knock poses similar problems. Cowart et al [37] defined the KOT as the instant where the predicted rate of temperature rise of the end-gas exceeded $6 \times 10^{6} \mathrm{~K} / \mathrm{s}$. Nakano et al [36] investigated the use of such a criterion and found that none of their predicted end-gas temperatures experienced such a large rate of change. As an altemative, they defined the knock onset time as the instant when the unburned gas temperature exceeded 1200K. Chun et al [17] and Brussovansky et al [35] used a more sophisticated approach in which $\dot{T}$ was normalised by the unburned gas temperature and compared to the reciprocal of the sound transit time across the cylinder. Alternatively, Moses et al [26] defined the KOT as the instant when $10 \%$ of the end-gas was reacted.

Methods defining the KOT in terms of the mass fraction of fuel consumed by the pre-flame reactions can produce reasonable results because, when knock is modelled as the spontaneous autoignition of the end-gas, the point where $10 \%$ of the fuel is consumed often coincides with the onset of the second stage ignition. This is demonstrated in Fig. 9 where it is clear that the first stage ignition process has consumed approximately $10 \%$ of the fuel. Fig. 11 shows typical predicted end-gas temperatures and the corresponding heat release rate for the adiabatic core region. The results show that the rates of increase in the volumetric HRR and the endgas temperature are extremely rapid after 378 CAD. Therefore, methods defining the KOT as the instant where the end-gas attains a specified temperature are going to be reasonably accurate because the rates of change at these times are extremely large. Any error in the choice of temperature will result in small errors provided that the value specified corresponds to end-gas temperatures typical of the rapid heat release phase. 


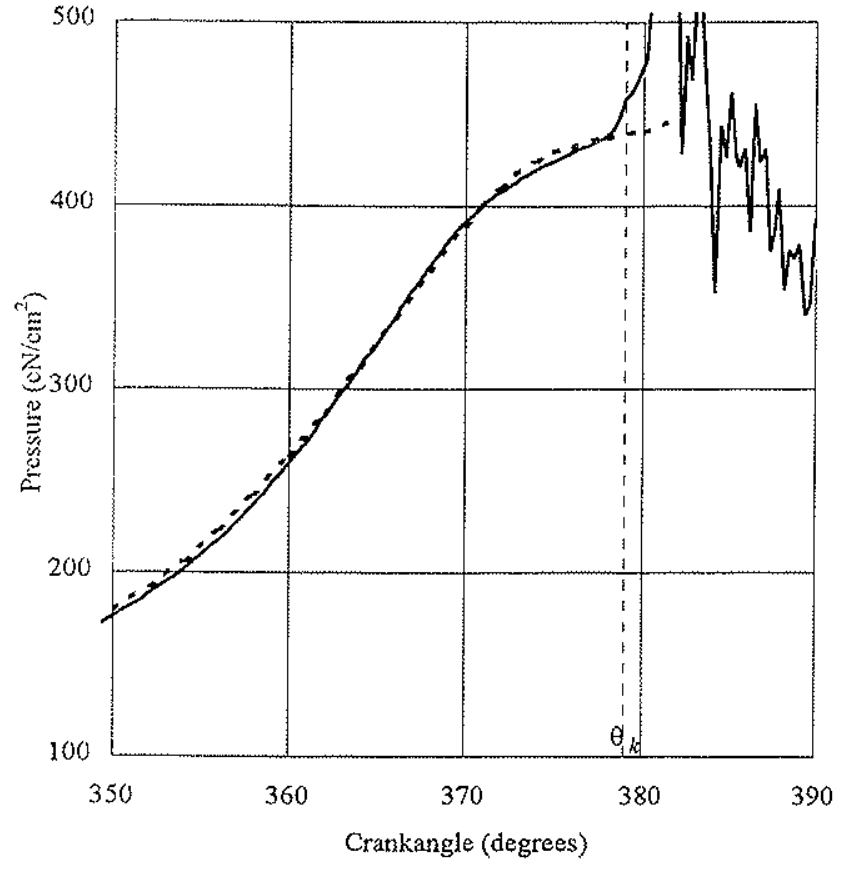

Fig. 12 Predicted and measured cylinder pressure for a knocking cycle showing KOT according to Kalghatgi's criterion [14].

(Simulated results plotted with a heavy dashed line)

Bradley et al [78] and Kalghatgi et al [77] showed that the KOT (defined from filtered pressure crankangle diagrams) was closely related to the maximum volumetric HRR due to the interactions between the acoustic waves and multiple autoigniting ETCs. The rate of temperature rise in the endgas is directly related to the volumetric HRR and methods employing such a criterion in the definition of KOT are effectively monitoring this. However, methods in which the absolute unburned gas temperature or the mass fraction of fuel reacted are used as criteria for defining the KOT are not accounting for the primary knock inducing phenomena and, as a result, could be erroneous when applied outside very controlled circumstances. Based on these observations, a critical value for the volumetric HRR has been selected in this work above which knock is assumed to occur. From Fig. $1 \mathrm{I}$, it can be seen that the volumetric HRR increases extremely rapidly after $379 \mathrm{CAD}$. Maximum volumetric HRRs in ETCs in the end-gas have been estimated as being between 50 and $400 \mathrm{GW} / \mathrm{m}^{3}$ for typical knocking cycles of higher octane parafinic fuels [78]. If the rate of increase in the volumetric HRR continues to rise, it is expected that these values will be attained in a few degrees. As a result a value of $20 \mathrm{GW} / \mathrm{m}^{3}$ has been selected as this falls in the region of rapidly increasing volumetric HRR for all the cases simulated in this study. It is felt that this method will give predicted knock onset times within 1 or 2 degrees of the actual event defined using Kalghatgi's method for ascertaining the KOT from filtered pressure crankangle diagrams.

Validation of the knock model is effected by comparison of simulated pressure crankangle diagrams and knock onset
Table 2: Ricardo E6 optical access research engine specification, operating conditions and empirical input for simulations.

\section{Engine specifications:}

No. of cylinders 1

Bore $(\mathrm{cm}) \quad 7.62$

Stroke $(\mathrm{cm}) \quad 11.1$

Con. rod length $(\mathrm{cm})$

Crevice volume (cc) N/A

Compression ratio* $\quad 10.47$

Combustion chamber shape Pancake

Spark plug position Offset

IVC (CAD) 215.0

Operating conditions:

Speed (rpm.) 1200

Equivalence ratio $\quad 0.88$ (rich)

Throttle Wide open

Empirical input:

Residual mass fraction $\quad 0.06$

Turbulence generation (Swirl ratio) $\quad 2.25$

Wall temps. $(\mathrm{K})^{* *}$ : head 470

liner 420

Temperature at IVC (K) $\quad 352$

Pressure at IVC (bars) $\quad 1.0$

* Measured in calibration tests [14]

** Estimated

times with those measured in a Ricardo E6 engine modified to allow for optical access. The data was provided by Shell Research in Thornton and the experimental apparatus and methods used have been published in detail elsewhere [14],[77]. Engine specifications, operating conditions and empirical input for the engine cycle simulations are summarised in Table 2. Fig. 12 compares a predicted

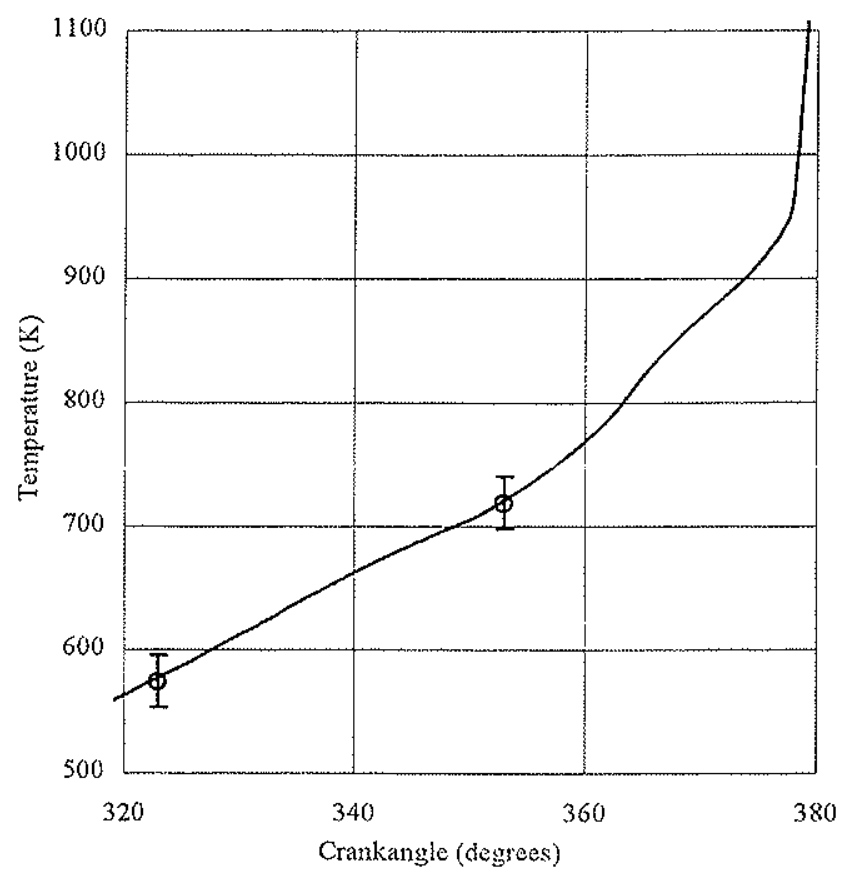

Fig. 13 Predicted and measured end gas temperatures. Measured values [14] shown with error bars. 


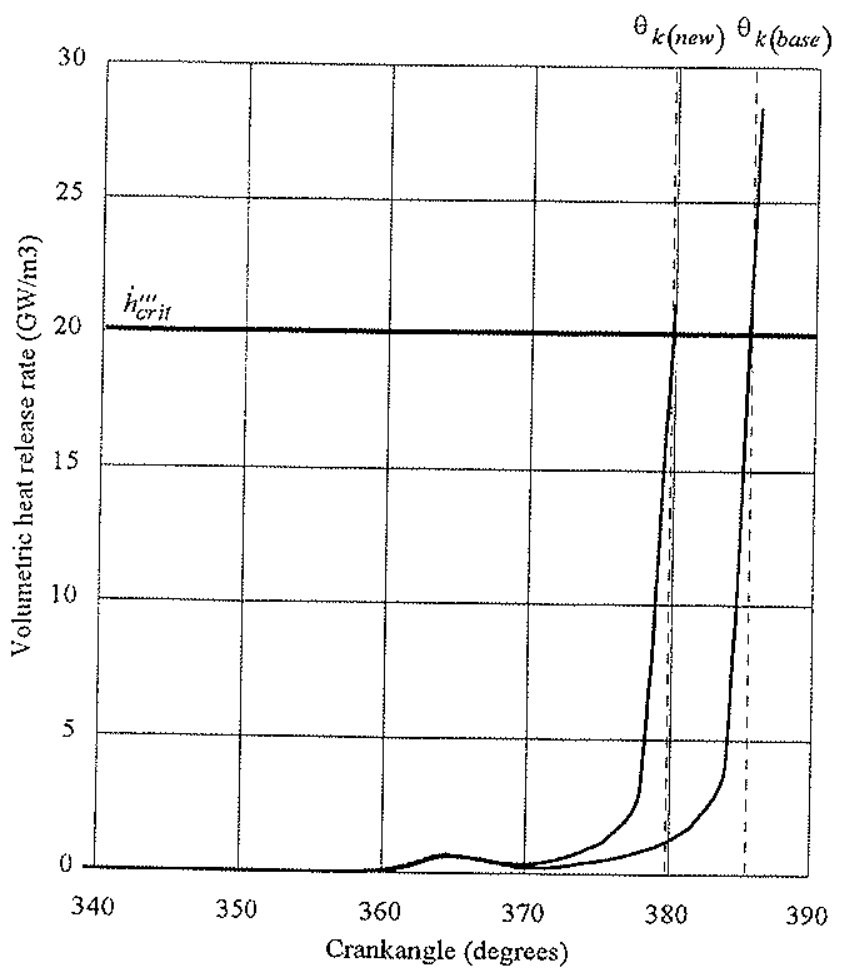

Fie. 14 Predicted volumetric heat release rates.

pressure-crankangle diagram up to the onset of knock with a measured one for a cycle exhibiting heavy knock. Good agreement is achieved. Ascertaining the precise cylinder pressure at inlet valve closure (IVC) from the pressure crankangle diagrams is difficult as the primary data was collected using a piezo electric pressure transducer. Such cquipment can only measure changes in pressure. Absolute pressures are computed by assuming that the cylinder pressure is equal to the intet manifold pressure at bottom dead centre. The pressure measurements are then shifted' accordingly. Kalghatgi et al [77] assigned a value of 1.013 bars at this point in the cycle. In order to arrive at a pressure at IVC for use as a model initial condition, several $\Delta$ imulations of the compression stroke were performed in which the pressure at IVC was adjusted until good agreement was achieved with measurements at the time of ignition. The initial temperature was chosen so that the predicted end-gas temperatures agreed with CARS temperature measurements $[1+\mid$ made during the compression stroke. Comparison between the measurements and the simulated temperatures is given in Fig. 13. The combined model predicted the KOT as ise CAD (Fig. 14. symbol $0_{k \text { (bise) }}$ ). Li et al $|23|$ were only able to validate the second stage ignition delay for nheptanc/air mixtures. In order to achieve good agreement for this case they had to lower the Arrhenius parameter in the chain branching reaction

$$
\mathrm{H}_{2} \mathrm{O}_{2}+\mathrm{M} \Rightarrow 2 \mathrm{OH}^{*}+\mathrm{M}
$$

to 0.6 times the value used in refs. [17], 134], [35], ,36], |37]. In the absence of validation as to the applicability of the value suggested by Li et al [23] for the Arrhenius parameter for the above reaction in the case of the autoignition of iso- octane/air mixtures. the value of 17.1 used elsewhere ([17],1341,135].[36],137|) is employed here. Fig. If also shows the HRR profile predicted using lhe modificd rersion of Li et a/'s model [2.3]. The prediction of the KOT is much improved and is in close agreement with the measured value (marked with the symbol ${ }_{k(m)}$ in Fig. 14).

\section{PREDICTING CYCLIC VARIATIONS IN THE KNOCK ONSET TIME}

As discussed in the introduction. it is generally accepted that the rates of pre-flame reactions are dependent on the temperature of the unburned gas |9|. The endmas temperature is susceptible to cyclical variations as a result of differences in the rates of flame propagation. residuals etc. giving rise to the variations in the KOT noted in many previous studies $|17|$ || $18|| 37 \mid$. . In the current work. we have used the combined model to investigate the correlation between cyclic variations in the burn rate and the KOT.

Keck et al $[79$ ) investigated the factors responsible for cyclic variations. They concluded that the carly flame desclopment showed considerable differences duc to variations in many parameters such as the local turbulence field. mean flow, gas temperature and mixture composition. Additionally. they noted that the fast burning phase of combustion was not significantly affected by such localised phenomena due to averaging over the flame front area. This work was extended by Pischinger and Heywood $|80|$ who attributcd $80 \%$ of the variability in combustion to variations in the formation of the flame kernel. They concluded that this was a result of varying heat losses to the spark plug electrodes duc to flame kernel displacements by the varying local flow field. Models for the early flame development are in existence |81|.|82| but

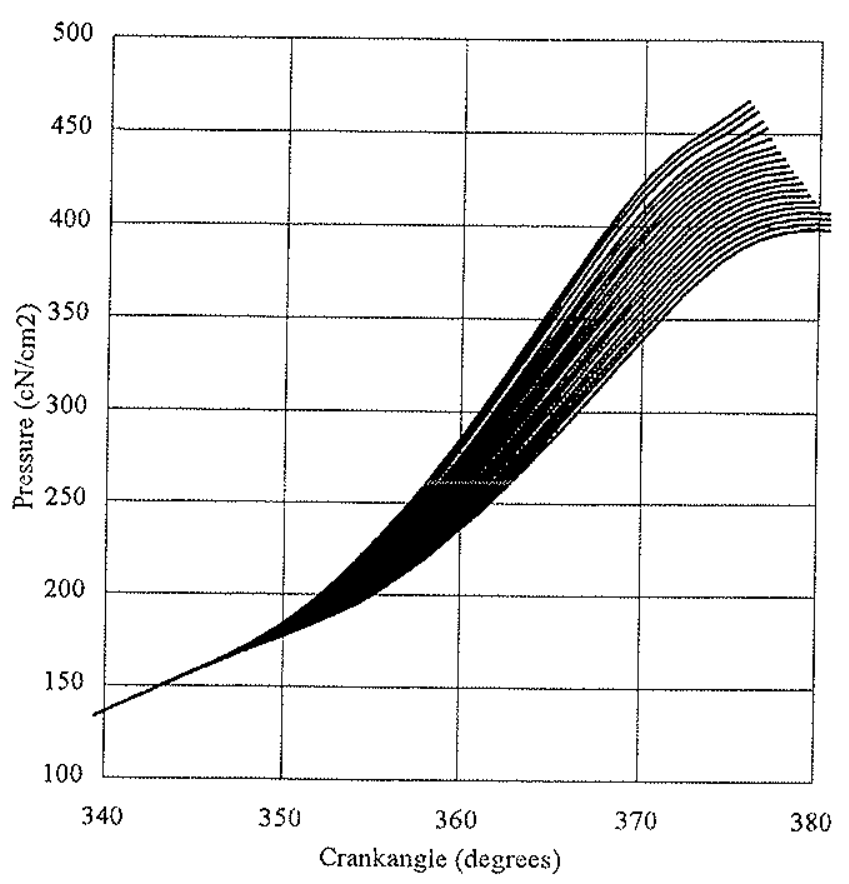

Fig. 15 Predicted cyclically varying pressurc crankangle diagrams. 


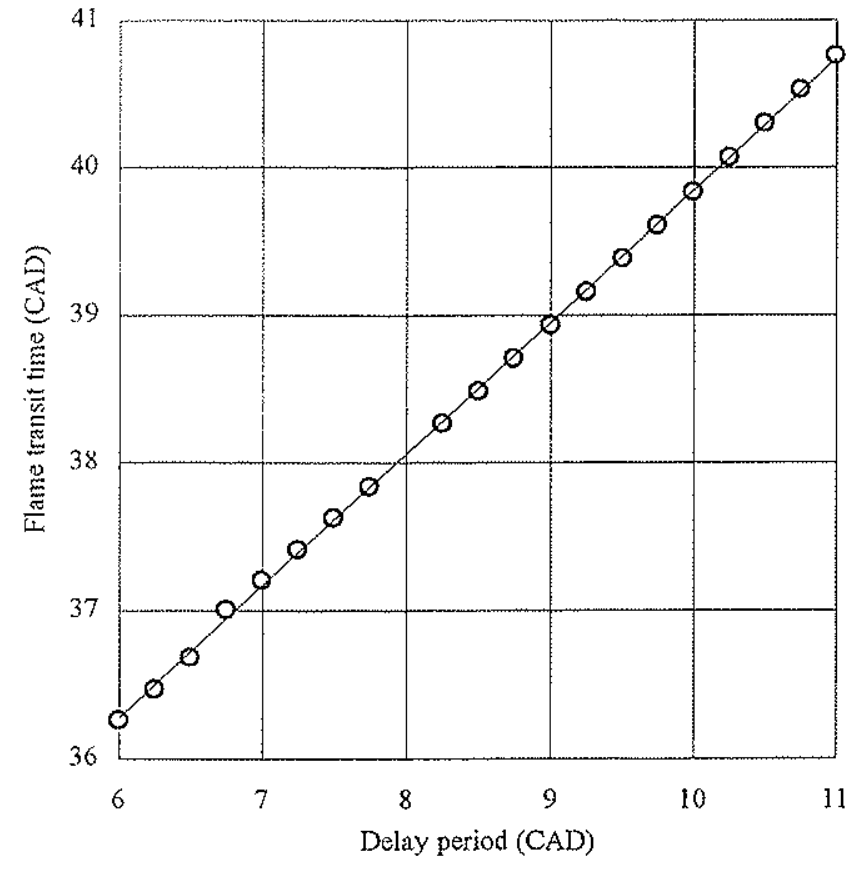

Fig. 16 Predicted flame transit times to a point on the cylinder head surface $6 \mathrm{~cm}$ from the spark plug electrode gap with different delay periods.

require considerable empirical input. In order to account for cyclic variability without employing the complex models for the kernel formation period, an approach similar to that used by Kumar et al [83] is applied here. They examined high speed photographs of the flame propagation in 15 to 30 consecutive engine cycles to arrive at a mean crankangle at which the flame radius was $9 \mathrm{~mm}$ from the spark plug. Cyclic variations in the time at which the flame radius equalled $9 \mathrm{~mm}$ in individual cycles was defined as ignition

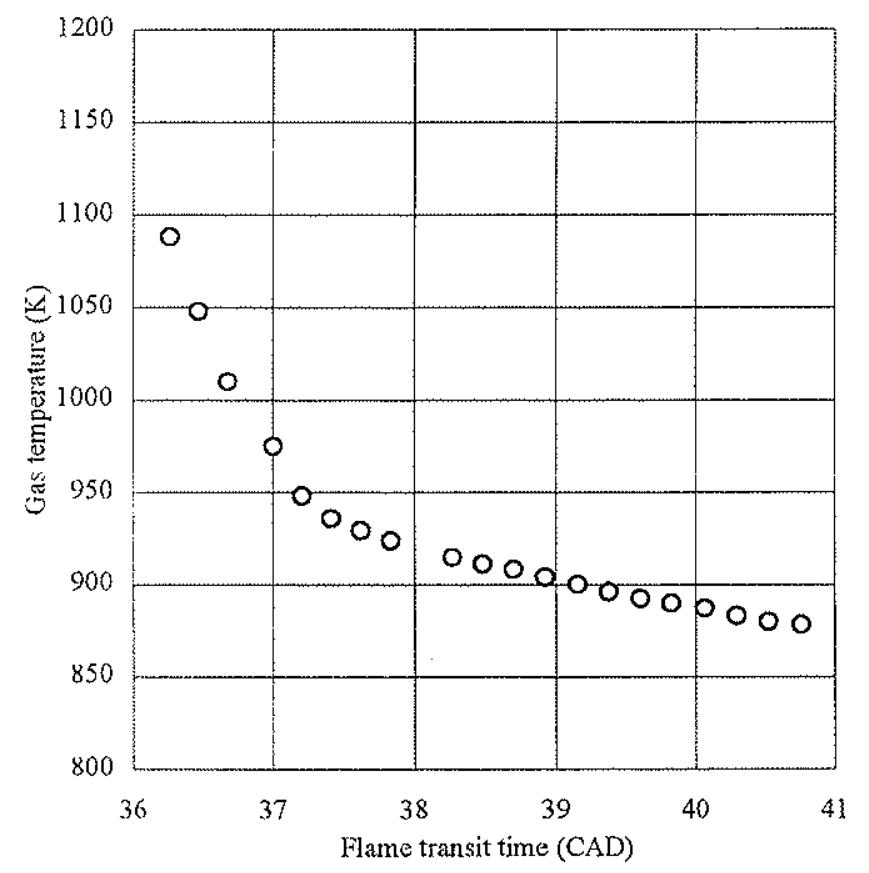

Fig. 17 Predicted core end-gas temperatures at $375 \mathrm{CAD}$ against flame transit time.

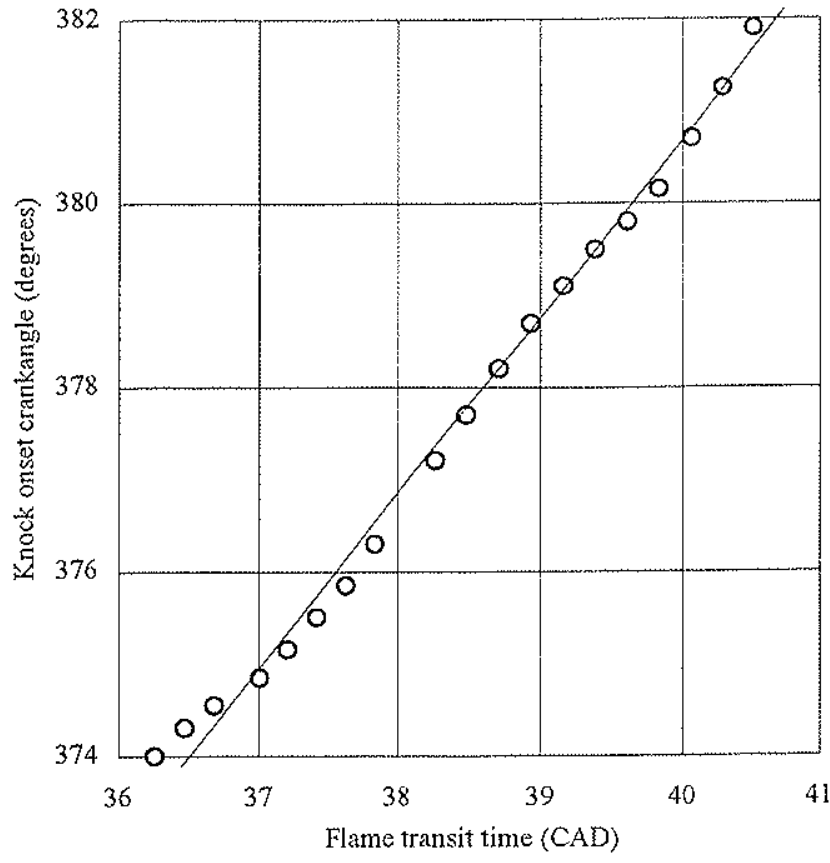

Fig. 18 Predicted KOT against flame transit time.

lag. They analysed their experimental data to obtain the variance in this lag. For the case studied at $1200 \mathrm{mpm}$ with low swirl, a variance of $3.2 \mathrm{CAD}$ was computed. They incorporated the observed statistical parameters for the cyclic variation of the early flame growth period by varying the effective ignition times.

To facilitate such effects in the current model, a delay period is specified corresponding to the time (in crankangle degrees) for the formation of a spherical kemel with a mass of $5 \times 10^{-6}$ $\mathrm{g}$ corresponding to a flame radius of 1-2 mm. Following [83], 21 computer runs were made where the delay period was altered from 6 degrees to 11 degrees in 0.25 degree steps. All other operating conditions and empirical input remained the same as detailed in Table 2 . The resultant predicted pressure crankangle diagrams for the 21 simulations are shown in Fig. 15. There are obvious. differences in the rate of pressure rise and the maximum pressure attained before the onset of knock. Fig. 16 demonstrates the trend between the delay period and the flame transit time to a point on the cylinder head surface 6 $\mathrm{cm}$ from the spark plug electrode gap. As expected cycles with shorter delay times have shorter flame transit times indicative of faster burning cycles. Fig. 17 shows the relationship between the temperature of the end-gas in the adiabatic core region and the flame transit time. As noted by Kalghatgi et al [14] with their CARS temperature measurements, higher temperatures were attained during the faster burning cycles due to the higher rates of pressure rise and correspondingly increased rates of heat release by preflame reactions. The resultant effect on the KOT is shown on Fig. 18 where the KOT (as defined above for this work) is plotted against the flame transit time. A linear best fit line is also shown. Again, agreeing with experimental observations 


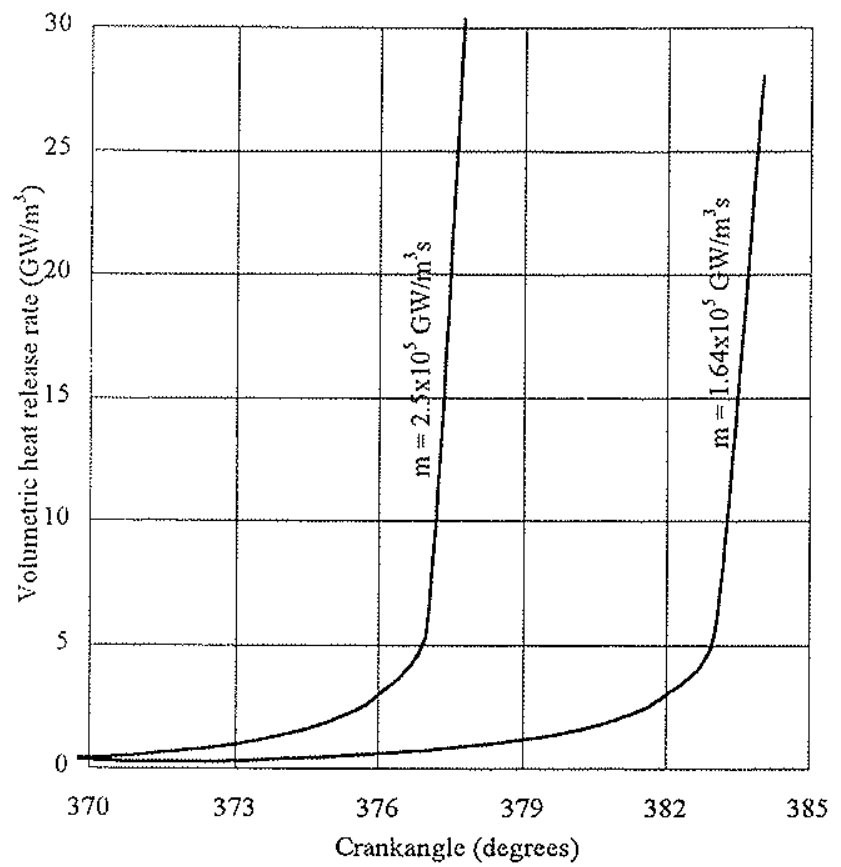

Fig. 19 Predicted volumetric heat release rates for similar cycles with different heat release rates.

([18],[84]), faster burning cycles are predicted to knock earlier in the cycle.

Experimental studies have also shown that cycles with earlier KOTs exhibited greater knock intensities [5],[18]. Fig. 19 shows the heat release profiles corresponding to the cycles with delay periods of $8 \mathrm{CAD}$ and $11 \mathrm{CAD}$. As expected, the simulation with the shorter delay period was predicted to knock first. Also shown are lines corresponding to the approximate gradients in the volumetric HRR curves at the onset of the rapid HRR phase. It can be seen that the cycle knocking earliest shows a more rapid rate of increase in the volumetric HRR as defined by the gradients $m$ in Fig. 19. Bradley et al [78] noted that the knock events with higher yolumetric HRRs are more likely to approach the more sidamaging ([6]) developing detonation mode of autoignition. From this, it can be concluded that, when the end-gas temperature is higher, knock occurs sooner and with more rapidly increasing HRRs increasing the likelihood of the autoignition occurring in the developing detonation mode giving rise to greater knock intensities.

\section{CONCLUSIONS}

A model for the compression, combustion and expansion processes in a spark ignition engine in which the near wall temperature gradients are accounted for has been developed and validated against data from a Ricardo E6 single cylinder research engine. This model has been coupled with an existing reduced chemical kinetic model for the low temperature ignition chemistry of mixtures of iso-octane, air and residuals. The model was shown to accurately predict the onset of knock after adjustment of the Arrhenius parameter for the chain branching reaction.

The combined model has been successfully employed to simulate cyclically varying knock. The relationship between the flame transit time to a point $6 \mathrm{~cm}$ from the spark plug electrode gap and the knock onset time has been shown to be approximately linear for the examples studied here. Finally the model has been shown to be able to subjectively demonstrate the phenomena responsible for the trend of increased knock intensities in earlier knocking cycles.

\section{SYMBOLS}

$C_{p} \quad$ specific heat capacity

$D_{3}$ fractal dimension

E activation energy

$G_{\rho k} \quad$ turbulence generation

$h \quad$ enthalpy

$H$ instantaneous clearance height

$k \quad$ turbulence kinetic energy

$l_{\max } \quad$ maximum fractal cut-off length

$l_{\min } \quad$ minimum fractal cut off length

$n \quad$ pressure exponent

$N \quad$ species

$P \quad$ pressure

Pr Prantle number

$q \quad$ specific heat transfer

$r_{f} \quad$ flame radius

$R \quad$ specific gas constant

$\widetilde{R} \quad$ molar gas constant

$R^{ \pm} \quad$ rates of reaction

$S_{h} \quad$ enthalpy source terms

$t \quad$ time

$T$ temperature

$u \quad$ flame speed

$u^{\prime} \quad$ turbulence intensity

$U$ mean flow velocity

$w \quad$ work

$x \quad$ distance

$\delta$ distance

$\varepsilon \quad$ turbulence dissipation rate

$\theta \quad$ crankangle

$\lambda$ thermal conductivity

$\mu$ viscosity

$\rho$ density

$\tau_{i j} \quad$ Reynolds stress tensor

$\phi \quad$ normalised air/fuel ratio

$\ell_{i} \quad$ turbulence integral length scale

\section{Subscripts}

\begin{tabular}{ll}
\hline$l$ & state 1 \\
2 & state 2 \\
$a$ & autoignition \\
$k$ & knock \\
$l$ & laminar \\
$t$ & turbulent \\
$T$ & total \\
$u$ & unburned state
\end{tabular}




\section{REFERENCES}

1. Affleck W.S. and Fish A., "Knock: Flame Acceleration or Spontaneous Ignition?" Comb. and Flame, Vol. 12, pp. 243$252,1968$.

2. Cuttler D.H. and Girgis N.S., "Photography of Combustion During Knocking Cycles in Disc and Compact Chambers," SAE Paper 880195, 1988.

3. Stiebels B., Schreiber M. and Sadat Sakak A., "Development of a New Measurement Technique for the Investigation of End-Gas Autoignition and Engine Knock," SAE Paper 960827, 1996.

4. Griffiths J.F. and Nimmo W., "Spontaneous Ignition and Engine Knock Under Rapid Compression," Comb. and Flame, Vol. 60, pp. 215-218, 1985.

5. Konig G. and Sheppard C.G.W., "End-Gas Autoignition and Knock in a Spark Ignition Engine," SAE Paper 902135, 1990.

6. Konig G., Maly R.R., Bradley D., Lau A.K.C. and Sheppard C.G.W., "Role of Exothermic Centres on Knock Initiation and Knock Damage," SAE Paper 902136, 1990.

7. Zeldovich YA. B., "Regime Classification of an Exothermic Reaction with Nonuniform Initial Conditions," Comb. and Flame, Vol. 39, pp. 211-214, 1980.

8. Pan J. and Sheppard C.G.W., "A Theoretical and Experimental Study of the Modes of End-Gas Autoignition Leading to Knock in S.I. Engines," SAE Paper 942060, 1994.

9. Gabano J.D., Kageyama T., Fisson F. and Leyer J.C., "Experimental Simulation of Engine Knock by Means of a Preleated Static Combustion Chamber," 22nd Symposium (International) on Combustion, pp. 447-454, The Combustion Institute, 1988.

10. Lucht R.P., Teets R.E., Green R.M., Palmer R.E. and Ferguson C.R., "Unburned Gas Temperatures in an Internal Combustion Engine. I: Cars Temperature Measurements," Comb. Sci. and Tech. Vol. 55, pp. 41 61, 1987.

11. Ferguson C.R., Green R.M. and Lucht R.P." "Unburned Gas Temperatures in an Internal Combustion Engine. II: Heat Release Computations," Comb. Sci. and Tech. Vol. 55, pp. 63$81,1987$.

12. Hoffmann F., Bauerle B., Behrendt F. and Warnatz J., "2D-LIF Investigation of Hot Spots in the Unburnt End Gas of I.C. Engines Using Formaldehyde as Tracer," International Symposium, COMODIA 94, pp. 517-522, 1994.

13. Nakada T., Itoh T and Takagi Y., "Application of CARS to Development of High Compression Ratio Spark Ignition Engine," SAE Paper 932644, 1993.

14. Kalghatgi G.T., Snowdon P. and McDonald C.R., "Studies of Knock in a Spark Ignition Engine With CARS Temperature Measurements and Using Different Fuels," SAE Paper 950690 , 1995.

15. Nakiada T., Kokita $H$. and Itoh $T$, "Effect of Uniformity in Mixture Strength and Unburned Gas Temperature in a Spark Ignition Engine," International Symposium, COMODIA 94, pp. 177-182, 1994.

16. Griftiths J.F., Halford-Maw P.A. and Rose D.J., "Fundamental Features of Hydrocarbon Autoignition in a Rapid Compression Machine," Comb. and Flame, Vol. 95, pp. 291-306, 1993.

17. Chun K.M, Heywood J.B. and Keck J.C., "Prediction of Knock Occurrence in a Spark-Ignition Engine," 22nd Symposium (International) on Combustion, pp. 455-463, The Combustion Institute, 1988.

18. Bradley D., Kalghatgi G.T., Morley C., Snowdon P. and Yeo J., "CARS Temperature Measurements and the Cyclic Variability of Knock in Spark Ignition Engines," 25th Symposium (International) on Combustion, pp. 125-133, The Combustion Institute, 1994.

19. James E.H., "Temperature Gradients in Spark Ignition Engine Combustion Chambers," SAE Paper 800458, 1980.

20. James E.H., "Further Aspects of Combustion Modelling in Spark Ignition Engines," SAE Paper 900684, 1990.
21. Jenkin R.J., James E.H. and Malalasekera W.M., "Modelling Near.Wall Temperature Gradients in 'Motored' Spark Ignition Engines," SAE Paper 960070, 1996.

22. Jenkin. R.J., James E.H. and Malalasekera W.M., "Modelling the Effects of Operating Conditions, Combustion and Turbulence on the Near-Wall Temperature Gradients in the Cylinders of Spark Ignition Engines," To be Submitted to Journ. of Instn. Mech. Engrs.

23. Li H., Miller D.L. and Cemansky N.P., "Development of a Reduced Chemical Kinetic Model for Prediction of Preignition Reactivity and Autoignition of Primary Reference Fuels," SAE Paper 960498, 1996.

24. Minetti R., Ribaucour M., Carlier M., Fittschen C. and Sochet L.R., "Experimental and Modelling Study of Oxidation and Autoignition of Butane at High Pressure," Comb. and Flame, Vol. 96, pp. 201-211, 1994.

25. Leppard W.R., "A Detailed Chemical Kinetics Simulation of Engine Knock," Comb. Sci. and Tech., Vol. 43, pp. 1-20, 1985.

26. Moses E., Yarin A.L. and Bar-Yoseph P., "On Knocking Prediction in Spark Ignition Engines," Comb. and Flame, Vol. 101, pp. 239-261, 1995.

27. Westbrook C.K., Warnatz J. and Pitz W.J." "A Detailed Chemical Kinetic Reaction Mechanism for the Oxidation of Iso-Octane and n-Heptane Over an Extended Temperature Range and Its Application to the Analysis of Engine Knock, 22nd Symposium (International) on Combustion, pp. 893-901, The Combustion Institute, 1988

28. Axelsson E.I., Brezinsky K., Pitz W.J. and Westbrook C.K. "Chemical Kinetic Modelling of the Oxidation of Large Alkane Fuels: n-Octane and Iso-Octane," 21 st Symposium (International) on Combustion, pp. 783-793, The Combustion Institute, 1986.

29. Westbrook C.K., Pitz W.J. and Leppard W.R., "The Autoignition Chemistry of Paraffinic Fuels and Pro-Knock and Anti-Knock Additives: A Detailed Chemical Kinetic Study," SAE Paper 912314, 1991.

30. Kirsch L.J. and Quinn C.P., "A Fundamentally Based Model of Knock in the Gasoline Engine," 16th Symposium (International) on Combustion, pp. 233-244, The Combustion Institute, 1976.

31. Hirst S.L. and Kirsch L.J., "The Application of a Hydrocarbon Autoignition Model in Simulating Knock and Other Engine Combustion Phenomena" Combustion Modelling in Reciprocating Engines, pp. 193-229, Plenum Press, New York, 1980.

32. Halstead M.P., Kirsch L.J. and Quinn C.P., "The Autoignition of Hydrocarbon Fuels at High Temperatures and PressuresFitting of a Mathematical Model," Comb. and Flame, Vol. 30 p. $45,1977$.

33. Griffiths J.F., Jiao Q., Schreiber M., Meyer J. and Knoche K.F." "Development of Thermokinetic Models for Autoignition in a CFD Code: Experimental Validation and Application of the Results to Rapid Compression Studies," 24th Symposium (International) on Combustion, pp. 1809-1815, The Combustion Institute, 1992.

34. $\mathrm{Hu} \mathrm{H}$. and Keck J., "Autoignition of Adiabatically Compressed Combustible Gas Mixtures," SAE Paper 872110, 1987.

35. Brussovansky S., Heywood H.B. and Keck J.C., "Predicting the Effects of Air and Coolant Temperature, Deposits, Spark Timing and Speed on Knock In Spark Ignition Engines," SAE Paper 922324, 1992.

36. Nakano M, Nakahara S., Akihama K., Kobo S. and Yamazahi S., "Predictions of the Knock Onset and the Effects of Heat Release Pattern and Unburned Gas Temperature on "Torque at Knock Limit in S.I. Engines," SAE Paper 952408, 1995.

37. Cowart J.S., Keck J.C., Heywood J.B., Westbrook C.K. and Pitz W.J., "Engine Knock Predictions Using a Fully-Detalled Mechanism and a Reduced Chemical Kinetic Mechanism," 23rd Symposium (International) on Combustion, pp. 1055 1062. The Combustion Institute, 1990. 
38. Li Y.., Miller D.L. and Cernansky N.P., "A Study on the Application of a Reduced Chemical Reaction Model to Motored Engines for Heat Release Prediction," SAE Paper $922328,1992$.

39. Li H., Prabhu S.K., Miller D.L. and Cernansky N.P., "Autoignition Chemistry Studies on Primary Reference Fuels in a Motored Engine," SAE Paper 942062, 1994.

40. Tomita E., Hamamoto $Y$. and Jiang D., "Temperature and Pressure Histories of End-Gas Under Knocking Conditions in a S.I. Engine," International Symposium, COMODIA 94, pp. 183-188, 1994

41. Chun K. M. and Heywood J.B., "Estimating Heat-Release and Mass-of-Mixture Burned from Spark Ignition Pressure Data," Comb. Sci. and Tech., Vol. 54, pp. 133-143, 1987.

42. Lucht R.P., Walter T., Dunn-Rankin D., Dreir T. and Bopp S.C., "Heat Transfer in Engines: Comparison of CARS Thermal Boundary Layer Measurements and Heat Flux Measurements," SAE Paper 910722, 1991.

43. James E.H., "Laminar Burning Velocities of Iso-Octanc-Air Mixtures - A Literature Overview," SAE Paper 870170, 1987.

44. Heimel S. and Weast R.C., "Effect of Initial Mixture Temperature on the Burning Velocity of Benzine-Air, n Heptane-Air and iso-Octane-Air Mixtures," 6th Symposium (International) on Combustion. 1957, The Combustion Institute.

5. Lancaster D.R., Krieger R.B., Sorensen S.C. and Hull W.L., "Effects of Turbulence on Spark-Ignition Engine Combustion," SAE Paper 760160, 1976.

46. Metghalchi M. and Keck J.C. "Buming Velocities of Mixtures of Air With Methanol, Iso-Octane and Indoline at High Pressure and Temperature," Comb. and Flame, 1982, 48.

47. Gouldin F.C., "An Application of Fractals to Modelling Premixed Turbulent Flames," Combustion and Flame, Vol. 68, pp. $249-266,1987$.

48. Mantzaras J., "Geometrical Properties of Turbulent Premixed Flames: Comparison Between Computed and Measured Quantities," Comb. Sci. Tech., Vol. 86, pp.135-162, 1992.

49. Mantzaras J., Felton P.G. and Bracco F.V., "ThreeDimensional Visualization of Premixed-Charge Engine Flames: Islands of Reactants and Products; Fractal Dimensions; and Homogeneity," SAE Paper 881635, 1988.

50. North G.L. and Santavicca D.A., "The Fractal Nature of Premixed Turbulent Flames," Comb. Sci. and Tech., Vol. 72 , pp. 215-232, 1990.

51. Murayama $M$. and Takeno $T$., "Fractal Like Character of Flamelets in Turbulent Premixed Combustion," $22^{\text {nd }}$ Symposium (International) on Combustion, pp 551-559, The Combustion Institute, 1990

32. Chin Y-W, Matthews R.P., Nichols S.P. and Kiehne T.M., "Use of Fractal Geometry to Model Turbulent Combustion in SI Engines," Combust. Sci. and Tech., Vol. 86, pp. 1-30, 1992.

53. Gouldin F.C., Hilton S.M and Lamb T., "Experimental Evaluation of the Fractal Geometry of Flamelets," $22^{\text {nd }}$ Symposium (International) on Combustion, pp. 541-550, The Combustion Institute, 1990.

54. Wu C-M, Roberts C.E., Matthews R.D. and Hall M.J., "Effects of Engine Speed on Combustion in SI Engines: Comparison of Predictions of a Fractal Burning Model With Experimental Data" Trans. of SAE, Vol. 102, Sect. 3, pp. 2277-2291, 1993.

55. Arcoumanis C., Bae C.S. and Hu Z., "Flow and Combustion in a Four-Valve, Spark-Ignition Optical Engine," SAE Paper $940475,1994$.

56. Arcoumanis C., Hu. Z., Vafidis C. and Whitelaw J.H., "Tumbling Motion: A Mechanism for Turbulence Enhancement in Spark-Ignition Engines," SAE Paper 900060, 1990.

57. Haddaed O. and Denbratt I., "Turbulence Characteristics of Tumbling Air Motion in Four-Valve S.I. Engines and their Correlation with Combustion Parameters," SAE Paper 910478 , 1991 .
58. Saxena V. and Rask R.B., "Influence of Inlet Flows on the Flow Field in an Engine," SAE Paper 870369, 1987.

59. Daneyshar H. and Fuler D.E. "Definition and Measurement of 'Turbulence Parameters in Reciprocating I.C. Engines," SAE Paper 861529, 1986.

60. Liou T.-M., Hall M., Santavicca D.A. and Bracco F.V., "Lisex Doppler Velocimetry Measurements in Valved and Ported Engines," SAE Paper, 840375, 1984.

61. Liou T.-M. and Santavicca D.A., "Cycle Resolved Turbulence Measurements in a Ported Engine With and Without Swirl," SAE Paper 830419, 1983

62. Davis G.C. and Borgnakke C., "The Effect of In-Cylinder Flow Processes (Swirl, Squish and Turbulence Intensity) on Engine Efficiency - Model Predictions," SAE Paper 820045, 1982.

63. Puzinauskas P. and Borgnakke C., "Evaluation and Improvement of a Unsteady Heat Transfer Model for Spark Ignition Engines," SAE Paper 910298. 1991.

64. Morel T., Rackmal C.I., Keribasr R. and Jennings M.J., "Model for Unsteady Heat Transfer and Combustion in Spark Ignited Engines and its Comparison With Experiments," SAE Paper 880198,1988

65. Borgnakke C., Davis G.C. and Tabaczynski R.J., "Predictions of In-Cylinder Swirl Velocity and Turbulence Intensity for an Open Chamber Cup in Piston Engine," SAE Paper 810224, 1981.

66. Hall M.J. and Bracco F.V., "A Study of Velocities and Turbulence Intensities Measured in Firing and Motored Engines," SAE Paper 870453, 1987.

67. Arcoumanis C.A., Bicen A.F. and Whitelaw J.H., "Effect of Inlet Flow Parameters on the Flow Characteristics in a FourStroke Model Engine," SAE Paper 820750, 1982.

68. Hall M.J. and Bracco F.V., "Cycle-Resolved Velocity and Turbulence Measurements Near the Cylinder Wall of a Firing S.I. Engine," SAE Paper $861530,3986$.

69. Pierce P.H., Ghandi J.B. and Martin J.K., "Near-Wall Velocity Characteristics in Valved and Ported Engines," SAE Paper $920152,1992$.

70. Foster D.E. and Witze P.O., "Velocity Measurements in the Wall Boundary Layer of a Spark Ignited Research Engine," SAE Paper 872105, 1987.

71. Heywood J.B., "Fluid Motion Within the Cylinder of Internal Combustion Engines -The 1986 Freeman Scholar Lecture," ASME Journ. of Fluids Eng., Vol. 109/3. 1987.

72. Witze P.O., Martin J.K. and Borgnakke C., "Measurements and Predictions of the Precombustion Fluid Motion and Combustion Rates in a Spark Ignition Engine," Trans. Soc. Auotomotive Engrs., Vol. 92, pp. 786-796, 1983.

73. Dao, K., Uyehara, O.A. and Myres, P.S., "Heat Transfer Rates at Gas-Wall Interfaces in Motored Piston Engine," Paper No. 760632, S.A.E., 1973.

74. Alkidas A.C., "Heat Transfer Characteristics of a SparkIgnition Engine," ASME Joun. of Heat Trans., Vol 102, pp. 189-193, 1980.

75. Henig Y., Addagarla S., Miller D.L., Wilk R.D. and Cemansky N.P., "Autoignition on n-Butane/Isobutane Blends in a Knock Research Engine," SAE Paper 890157, 1989

76. Witze P.O. and Geen R.M., "Determining the Location of End-Gas Autoignition Using Ionisation Probes Installed In the Head Gasket," SAE Paper 932645, 1993.

77. Kalghatgi G.T., Golombok M. and Snowdon P., "Fuel Effects on Knock, Heat Release and 'CARS' Temperatures in a Spark Ignition Engine," Comb. Sci. and Tech., Vols. 110-111, pp. 209-228, 1995.

78. Bradley D., Kalghatgi G.T. and Golombok M., "Fuel Blend and Mixture Strength Effects on Alitoignition Heat Release Rates and Knock Intensity in S.I. Engines;" SAE Paper $962105,1996$.

79. Keck J.C., Heywood J.B. and Noske G., "Early flame Development and Burning Rates in Spark Ionition Engines and 
Their Cyclic Variability," SAE Paper 870164, SAE Trans., Vol. 96, Sect. 4, pp. 162-175, 1987.

80. Pischinger S, and Heywood J.B., "How Heat Losses to the Spark Plug Electrodes Affect Flame Kernel Development in an SI-Engine," SAE Paper 900021, 1990.

81. Shen H., Hinze P.C. and Heywood J.B., "A Model For Flame Initiation and Early Flame Development in SI Engine and its Application to Cycle-to-Cycle Variations," SAE Paper 942049 , 1994.

82. Pischinger S. and Heywood J.B., "A Model for Flame Kernel Development in a Spark-Ignition Engine," $23^{\text {rd }}$ Symposium (International) on Combustion, pp 1033-1040, The Combustion Institute, 1990.

83. Kumar S., De-Zylva M.D. and Watson H.C., "Prediction of Cyclically-Variable Pressure-Time History of a SI Engine Using a Quasi-Dimensional Spherical Flame Front Model," SAE Paper 912454, 1991.

84. Lyon D., I, Mech. E. Paper No. C307/86, 1986. 